This report was prepared as an account of work sponsored by an agency of the United States Government. Neither the United States Government nor any agency thereof, nor any of their employees, makes any warranty, express or implied, or assumes any legal liabilily or responsibility for the accuracy, completeness, or usefulness of any information, apparatus, product, or process disclosed, or represents that its use would not infringe privately owned rights. Reference herein to any specific commercial product, process, or service by trade name, tradernark, manufacturer, or otherwise does not necessarily constitute or imply its endorsement, recommendation, or favoring by the Unittd States Government or any agency thereof. The views and opinions of authors expressed berein do not aecessarily state or reflect those of the United States Government or any agency thertof.

\title{
TRANSPORT SIMULATIONS OF OHMIC PELLET EXPERIMENTS ON THE TFI 7 , ASDEX, AND ALCATOR-C TOKAMAKS
}

\author{
M. H. REDI. W: M. TA.NG. D. K. OWENS. \\ Plasma Physics Laboratory. Princeton Lniversity. \\ Princeton. NJ 08543 \\ and \\ II. GREENWILD, \\ PPPL--2525 \\ Plasma Fusion Center, M. I. T. \\ DE88 01586 \\ Cambridge, MA 02139 \\ and \\ O. GRLBER and M. KALFMANN \\ Max-Planck-Institut für Plasmaphysik, \\ ELR.tTOM Association. D-8046 Garching, \\ Federal Republic of Germany
}

\begin{abstract}
Transport simulations of ohmic gas-fuelled and pelletfuelled experiments have been carried out to test a microinstability-based. profile-ronsistent model of anomalous transport in tokamaks. Predictions for experiments on the TFTH, ASDEX, and ALCATOR.C tokamaks were found consistent with the observed confinement and temperature measurements.
\end{abstract}

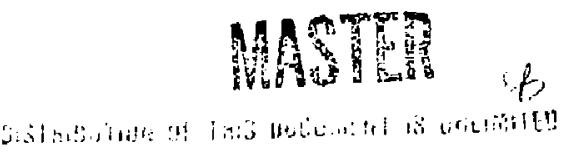




\section{INTRODUCTION}

I central prublem in plasma physics is understanding and improving the energy confinement of tokamak discharges. Measurements of the electron thermal confinement time indicate a large anomalous reduction: i.e.. $J_{e E}$ is usually less than one one-hundredich of neoclassically predicted levels. For the ions. the olsserved continement times are typically less than one-third of neuclassical estimates.

Transport simulations with recent theoretically based models 1 for these anomaluus electron and isn thermal losses have been found in good agreement with uhmic and neutral-beam-heated experiments on TFTR 2.3. In these simulations trapped-electron drift wave transport at low density was found in give rise to neo-Alcator scaling, and $\eta_{1}$-driven ion transpert was found consistent with the onset of density saturation of the total energy confinement time for large plasmas. Initial simulation studies of TFTR pellet-fuelled experiments were consistent with suppression of $\eta_{i}$-driven ion transport and improved confinement during the peaked profile phase following pellet injection. Kesults from recent measurements of density fluctuation properties $: 4.5^{\circ}$ tend to suppott the existence of the specific microscopic transport processes underlying the theoretical model studied here.

We have extended the tests of the microinstability-based models to ohmic experiments on ASDEX and ALCATOR-C using the BALDLR code 6 : Simulations of representative gas and peliet-fuelled discharges on these tokamaks have been carried out to see if the TFTR calibration of the theoretical mudel can be used for simulations of experiments on machines in different plasma parameter ranges. Analysis of pellet-fuelled experiments is of particular importance for developing a fusion reactor because significantly improved confinement has been observed for pellet-fuelled ohmic plasmas $: \bar{T}-9 !$ and because it is the only way to fuel most proposed reactors. Global confinement increases by about a factor of two for each of these tukamaks with pelletfuelling. At medium densities, where pellet fuelling dues not exceed the gasfuelling density limit, however, improved confinement with pellet injection is not seen 10 .

Each of the experiments considered has already been analyzed by the experimental team responsible for the data. The gral of this paper is to attempt to unify the modelling of the experiments using one theoretically. 
based model with no change in overall numerical cuefficients.

\section{MICROINSTABILITY-BASED MODELS FOR $\chi_{e}$ AND :}

The profile-consistent microinstability-based model for anomalous electron thermal diffusivity, $\gamma_{c}$, was originally introduced in Ref. 1 , and represents the effects of the trapped-electron mode in both collisional and collisionless regimes. As rone of the experiments simulated fell in the collisionless regime, only the collisional form of the electron diffusivity is discussed here. The model for anomalous ion thermal transport, $x_{2}$, was also presented origjnally in Ref. :1:. It is based on the excitation of the toroidal ion temperature gradient-driven instabilities ( $\eta_{i}$ modes).

The simulations in this paper are carrjed out with improved versions of the electron and ion diffusivities

$$
\chi_{e}^{\text {collisional }}(r)=\frac{4.3 \times 10^{3}\left(1-0.25 \alpha_{n}\right)\left(P_{\text {tot.e }}\right)^{0.8}}{n_{e o} R^{1.2} a^{0.1} Z_{e f f}^{0.2} B_{T}^{0.4} q_{c}^{0.9}} F_{e}(r) .
$$

and

$$
x_{2}^{\eta_{1}}(r)=\frac{5 \times 10^{3}\left(P_{\text {tol. }} / n_{2 o}\right)^{0.6}}{\left(B_{T} R q_{a}\right)^{0.8} a^{0.2}} F_{1}(r) .
$$

Here,

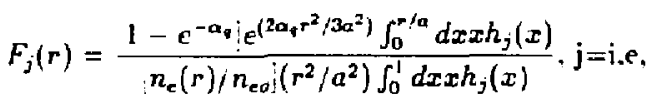

where $R(m), a(m), B_{T}(T), n_{e 0}\left(10^{20} / m^{3}\right), \alpha_{q}=q_{a}-0.5 . \alpha_{n}$ characterizes the density profile, $a_{n}=n_{0}\left(1-(r / a)^{2}\right)^{a_{n}}$, and $h_{j}(x)$ is the total electron or ion heating energy deposition profile. $P_{\text {tot },}(M W)$ is the net electron heating power from all plasma heating sources. In our simulations we subtract the radiated power and the electron-ion temperature equilibration energy loss from the ohmic electron heating contribution. $P_{\text {tot.d }}$ is the total ion heating power , and $h_{i}(x)$ is the jon heating deposition profile. The ion heating energy: deposition arises only from the electron-ion energy transfer in this study of ohmically heated plasmas.

The model was derived for steady-state ohmic equilibrium conditions. The normalization constants in these equations were obtained in simulations 
of TFTR ohmic experiments 23, it was found that the microinstability. based $x$, "nodel produces ion thermal transport roughly equivalent to using a factor of 3 for the neoclassical multiplier in the simulation studies of TFTli $?$

Xine that this formulation of the model. Eys. $(1-4)$. differs from that in Hef. 1 in that the diffusivities depend on the species-specific heatine power rather thin the wal heating power absorbed by the plasma. In high density pellet experiments the improved model $x_{1}$ will be larger: the toroidal iun instabilities will have increased power available through the exchange term. The improved. species-specific heating forms for $x_{e}$ and $x_{1}$ have been used to model both ohmir and neutral-beam-heated cases 3 with no change in numerical coefficients.

Ohmically healed TFTR cases have been simulated 2' with the original model 1. The improved rersion has already been used for the neutralbeam-heated cases studied in Kef. 3 and for the one collisionless ohmically heated case in Ref. ? For ohmically heated, gas-fuelled plasmas on TFTR this difference in formulation changes only the overall normalization in that simulation results for confinement and plasma temperatures are almost urchanged. However. for neutral-beam-heated plasmas, where the ion heating fraction becomes large. and for high density pellet-fuelled plasmas. where $Q_{a r}$ is significant in the elertron power balance. $Q_{e t}$, these two formulations are no longer equivalent. In Section 4 . 1 the power balance results for several simulation cases are presented for both of these models.

\section{SIMULATION RESULTS}

In Table I are shown the plasma parameters for the seven experiments simulated. The TFTR pellet-fuelled experiments simulated here are high current. large $R$ and $a$. three and five-pellet discharges. The three-pellet experiment was also analyzed in the TFTh uhmic simulations study 2 . This case has been reanalyzed with an improved version of the microinstaizility. based model.

The TFTl five-pellet case exhibited enhanced confinement for $0.8 \mathrm{sec}$ 9 . about $1.5 \times \tau_{E}$. Since this case did not have time-dependent density profiles available, we have at templed to simulate this shot by using the $i 6$-point Thomsun scattering density data (at 200 msec following the last pellet) for 
a time-independent "steady-state simulation." The two ASDEX experiments simulated are very similar multiple-pellet-fuelled shots. The ASDEX experiments are is particular interest as a steady-state peaked profile condition is maintained by multiple pellet injection in a divertor lokamak for as long as 1.1 sec.. l.t.. abuut $T \times T_{E}$. Where the relevant data were available. a reference gas-fuelled discharge at the same conditions of current. magnetic field. etc: was also simulated. The experiments on the ALCATOR-C tokamak are high tosoidal field. high density scenarios: a kwer density one-pellet discharge and a high current. very high density three-pellet discharge.

\subsection{Transport Modelling}

The BALDLK transport code 6: solves time-dependent radial diffusion equations to simulate the evolution of the current and particle densities and the electron and ion temperatures. Up to two species of hydrogen and four species of impurities can be handled by the multifuid code. Resistivity is assumed to be neoclassical. A Kadomtsev sawtooth model is used with the sawtonth period set to the measured period.

Particle densities are computed for all species. The particle flux includes both diffusive and advective effects. The source of particles arises from ionization of thermal neutrals and from pellet injection modelling 11,12. Recent analysis of enhanced confinement neutral-beam-heated discharges by Zarnstorf 13 indicates that an upper bound on the central ion convective multiplier is greater than or equal to $5 / 2$ and the central electron convective multiplier is between $3 / 2$ and $5 / 2$. However, at this time there is no general prescription for the convective multiplier appropriate for a particular tokamak in a given experimental scenario. The convective multiplier has been assumed to be $3 / 2$ in the simulations in this paper.

Except for TFTR shot 20259. for which complete time-dependent data were not available. all experiments were simulated to model the full time evolution of the experimental shot including the pre pellet gas-fuelled phase and the pellet injection phase, matching pellet size and injection times. Pellet velocities were adjusted tu give agreement with pellet perietration as measur-i on each experiment. These simulations included the evolution of current and line ayerage density. Empirical particle transport coefficients were adjusted tu give agreement with measured central and line average electron density: 
The BALDLR code was programmed to include oxygen impurities and the impurity transport coefficients were empirically adjusted tw match the observed values of $Z_{\text {efr }}$. The particle transport coefficient chusces are described in Section 4.3. The measured ratius of radiated to whmic heating power were used as well as the radiation profiles. whoch were available for the TFTR and 1SIDF.X experiments. Thus. these simulatuns represent the nust complete and detailed predictions of actual experimests currenty. pussible.

\subsection{Simmlations of TFTR Experiments}

Results from the time-dependent simulations of two TFTR experiments are shown in Table II. The TFTR three-pellet shot 18681 exhibits strong, transient current ramp conditions before pellet injection. However, a corresponding ohmic equilibrium, high current gas-fuelled shot was arailable for our analysis. shu 18673 (Table I).

These two cases were simulated with the total plasma heating model of Ref. I as part of a study '2: of a large number of TFTR ohmic experiments. Results from the simulations in this paper are not very different from thuse of Ref. 2. (see Section 4.1). The measured and predicted electron temperature and density profiles of the gas-fuelled case are shown in Fig. 1 . ('onfinement resılis. loop voltages, and electron temperatures are in good agreement for the gas phase.

Since the theoretical models for the diffusivities were based on steadystate assumptions $1-3$, difficulties can obviously be expected when attempting to simulate transient phenomena. This is illustrated by the simulation of the nonequilibrium three-pellet-fuelled plasma case at TFTR. The predicted central electron temperature was found to be $1.9 \mathrm{kel}$, compared to the measured central electron temperature of $1.5 \mathrm{kel}$. The calculated high electron temperature (Fig. 2) of the pust pellet TFTR simulation is attributed to the fact that the plasma is not in steady state. Specifically, the line average density decreases b. $20 \%$ wer an energy continement time following the last pellet while the plasma is continuing to reheat. In addition, an unstable condition ran develop in the species-specific model simulations if $Q_{e r}-P_{\text {rod }}$ beromes comparable to the ohmic heating power. as can happen for high density pellet-fuelled plasmas. This instability was seen to develup when the simulation of TFTh shot 18681 was run with ? $^{\text {ANOM }}=0$. 
In the one-pellet-fuelled simulation the $\eta_{1}$ parameter is seen to have dropped to 1.9. compared $t 13.9$ in the gas-fuclled reference case. In the

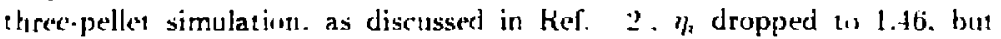
did nut exhilbit prolonged suppression belnw the critical walue of 1.5 . The relatively rapid density pumpout in TFTK and the particle confinement properties of this limiter tokamak caused a temporary dirop in $\eta_{\mathrm{t}}$. simultane. wus with the observed temporary increase in plasma continement. However. when the magnetie confinement data are averaged over a confinement time. a substantial increase in plasma confinement is not observed. These results are consistent with the $\eta$ model which does predict temporarily improved confinement with transiently peaked plasma density but no significanty improved sustained confinement.

The "steady-state" simulation of the TFTR five-pellet shot 20259 is of particular interest because $\tau_{E}^{\exp }-\overline{550} \mathrm{msec}$ over $0.8 \mathrm{sec} 9$. This should be compared to the 300 msec confinement time of the very high density gasfuelled deuterium and helium experiments. Figure 9 of Ref. '2 illustrates the improved confinement found for the 72 -cm TFTR pellet experiments. Shot 20259 has a very peaked density profile, $\alpha_{n}-3$, where $n_{c}=n_{0}\left(1-(r / a)^{2}\right)^{a_{n}}$. At $n_{e a}=3.0 \times 10^{20} \mathrm{im}^{3} . T_{e}$ and $T_{i}$ are strongly coupled and if $T_{e o}$ is the measured $1.4 \mathrm{ket} . \eta_{t}$ is found equal to 0.5 , averaged across the $q=1$ to $q=2$ surfaces. If the $\eta_{1}$ threshold is 1.5 , the anomalous ion losses are clearly suppressed in the TFTR five-pellet shot. The steady-state simulations show the increase of global confinement due to suppression of anomalous ion losses is $11 \%$ at this density. The measured increase in global confinement for the five-pellet shot compared to the "saturated" confinement level of the high density gas puff cases is $57 \%$. Thus, the improvement in confinement of the five-peliet high confinement shot obtained from the model is comparable to that found for the experiment. We do not present detailed results from the simulations of this case because we have not modelled the nonequilibrium reheating conditions or convective losses. which were about $10 \%$ of the total lusses in the three-pellet time-dependent simulation.

\subsection{Simulations of ASDEX Experiments}

Table I]] shows the simulation results for the two multipellet ASDEX experiments. In Fig. 3 is shown the evolution of the line-averaged den- 
sity un ASUEX fur shor 18876. The multi-pellet-fuelled. quasi-steady-state allows is more definitive test of the microinstability-based transport model and a cuantitative prediction of $\eta_{1}$-suppressed. improved confinement. The electron temperature profile predictions are compared wo Themson scattering measturements in Figs. $+-\bar{\tau}$. Predictions agree well with experiment in the ISI)EX pellet phases. The overall confinement predietions for the gas phase simulations are within 2010 \% agreement with data analysis results. The predictud elertron temperature profile shapes are in clear disagreement with the gas phase ubservations on this divertur machine. Since the line average density is increasing less than $10 \%$ over a confinement time at the end of the gas-fuelled prepellet phase (Fig. 1), this is not expected to be a factor in the temperature profile disagreement between data and modelling. The initial 1 assumption of a Gaussian temperature profile shape is cleariy incorrect for these experiments. For the limiter tokamaks studied. the temperature profiles are in reasmable agreement with measurements in both gas and pellet-fuelled phases.

The transient nature of most pellet experiments is the biggest potential drauback in applying the models for $\chi_{c}$ and $\chi_{i}$, which were derived for steadystate conditions. The ASDEX pellet experiments are not subject to this limitation. These were also experiments which showed a clear and prolonged transition in buth $\eta_{t}$ and $\tau_{E-} \eta_{i}$ drops from 2.0-3.0 in the gas phase to 0.2-1.0 in the peellet-fuelled phase for shot $18 \mathrm{i} 16$, depending on $r / 4$. The simulation results are close to the experimental values: $\eta_{t}$ is predicted to be about 3.0 in the gas phases and 0.3 and 1.0 in the two peller. phases simulated. The simulated confinement improwed from $73 \mathrm{~ms} \mathrm{t}, 138 \mathrm{~ms}$ for shot 18876 , and from $81 \mathrm{~ms}$ to $166 \mathrm{~ms}$ in the simulation of shot 18716 . This is in good agreement with the experimentally measured confinement improvement.

Figure 8 shows the electron and ion thermal diffusivities used in the simulations of ASDEX shot 18716 in the gas and pellet phases. In the pellet phase the model predicts the ion diffusivity to be nerclassical. Note that the shape of the ion diffusivity in the gas and pellet phases is very different. Buth electron and ion transport coefficients are redured in the pellet-fuelled phase in the confinement region $a / 3<r<2 a / 3$. In ASUEX, the increase in electron confinement time frum this mudel can be traced to the $1 / \pi_{r}$ behavion of $\lambda_{e}$ and the fact that $P_{c, t o t}$ was the same in the ASDEX gas and pellet fuelled phases. 
In these simulations where $\eta_{i}$ transport is more important during the gas phase than curing the pellet phase. the diffusivity protiles (Fig. 8) are similar to the results of Groebner $t$ al. 11 , wh", have shown from neutral-beamheated experiments on L-III where $\eta_{1}$ transport is expected $t$, be important 3 . That the ion diffusivity profile appears tw be more like the $x_{e}(r)$ profile than like the ion neoclassical diffusivity profile. Fonck 15 has reported that for balanced neutral-beam-heated supershots on TFTh. the ion temperature jrofile measurements indicate that $x_{1} \times(1-2) \times \chi_{r}$ is a good approximation. He also finds. from a preliminary analysis of $x_{z}$ and $x_{t}$ for ohmic experiments at the half radius, that the ratio of $\lambda_{1}$ to $\chi_{e}$ increases with plasma density 16. Although improved diagnostics are being developed. there is. as yet. little actual ion diffusivity data for ohmic experiments. precluding detailed comparisuns of model and experiment. We note however that $\chi_{i} / \chi_{e}$ at the half radius increases with the line average density in this case (Fig. 8).

\subsection{Simulations of ALCATOR-C Experiments}

Simulations of the ALCATOR-C pellet shots (Table I) predict confinement times and electron temperatures which agree with experiment within $20 \%$ (see Table If and Figs. 9 and 10). In ALCATOR-C shot 80, as in the TFTR three-pellet shot. the $\eta_{i}$ parameter does not fall below l.5 for a time iong compared to $\tau_{E}$. Again. although the predictions do not disagree

much with measurements. the results still do not constitute a severe test of the model. Like the TFTR three-pellet case. the lower density ALCATOR-C pellet-fuelled case was on the borderline for onset of $\eta_{i}$ transport: $\eta_{i}$ being 1.6 in our simulations. The higher density ALCATOR-C case had $\eta_{i}$ reduced to 0.4 . well below the critical value. Unfortunately, the gas phase of this high density shot was obtained during a current ramp. No corresponding ohmic equilibrium gas puff shot at this high current was available for comparison. Vote that the model correctly predicts the doubling of confinement for the high current, high density ALCATOR-C experiment compared to the lower density case.

In Table $V$ is shown a comparison of the electron temperatures and confinement predicted for several ion diffusivity models for these two ALCATORC cases. The microinstability model predictions can be compared to those for simulations in which ion diffusivity was assumed due to a) Chang-Hinton 
neenclassiral model only, b/ twice (hang-Hinton ion diffusivity, and c) four tinles: (hang-Hinton ion diffusivity: The experimental values are also shown. Is fuund by llidfe Ti . the ALC'ATOK-( gas-fuelled experiment corresponds 1. lareer ion lusses than can be accounted for by the Chang-Hinton theory alone. and pellet-fuelling reduces the anomalesus ion losses so that the total in lusses are at abuut the nenclassical level. The model predictions for

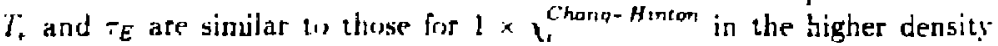
pellet-fiselled phase. The mudel predictions for $T_{\mathrm{e}}$ and $\tau_{E}$ in the gas phase case are cluser 10 experiment than predictions based on any multiplier of

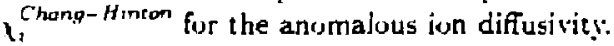

\section{DISCUSSION}

The agreement of $\tau_{E}$ and $T_{c}$ between simulation and experiment for the ALCATOR-C cases shows that the scaling of the theoretically based models for $x_{e}$ and $x_{\text {: }}$ can be applied to ohmically heated experiments on lokamaks other than TFTR with no significant change in the overall numerical factor. The ASDEX simulations constitute real tests of both the $x_{e}$ and $x_{1}$ models. as quasi-steady-state cases were simulated with $\eta_{i}$ above and below the critical value. For all three tokamaks with high density pellet fuelling. the simulations show improved ion energy confinement time because $\eta_{i}$ transport is suppressed. This trend is most clearly evident in the ASDFX simulations.

\subsection{Comparison of Original and Improved Diffusivity Models}

In Tables VI and $\mathrm{VIl}$ we see the effect on the energy balance of recasting the original model for $\chi_{e}$ and $\chi_{2} 1$ so thet power heating the electrons drives $\lambda_{2}$ and power heating the ions drives $x_{r}$. In Table $V l$ are simulation results using the improved model. Eqs. (4-i), and in Table VII are results obtained from simulations with the otiginal model 1 . The improved model changes the details of the power balance but has little effect on overall confinement and plasma temperatures except for the ASDEX pellet phase. where somewhat bette: agreement with experiment is seen.

The two models were calibrated ' 2 on TFTR ohmic data so that simulated confinement times were identical within $5 \%$. Kecently, it was discovered that the TFTR Thomson scattering system had been improperly calibrated 
dur to misinterpretation of a lamp standard. This resulted in an $\approx 1$ iti underestimation of $T$, during the run periods $19 \times 6 j-1987$. The effert on the lyais data is more complex. Kevised temperature data show that the ohmic casts on which the nundel was etalusced. Frum 198.1 data. have been undertstimaled by unly a few percent. Thus wur srerall conclusions and the model normalizations have not rhanged.

The ISUEX and ILC ATOR-C pellet simulations are more sensitive io the change in the furm of the power driving the diffusivity model. since ion lusse's are of mure importance in these high density cases. TFTH has weaker electron-ion coupling. is more collisionless than the other two tokamaks. and energy confinement losses are primarily due to $x_{e}{ }^{\text {NOM }}$. On ASDEX and ALCATOR-C the confinement lusses are balanced more equally between the electron and ion channels in the gas phase. The power balance in the ASDEX and ALCATOR-C gas puff simulations with the species-specific heating model shows ion losses becoming slightly stronger than with the original model. In the pellet phase on ASDEX and ALCATOR-C. the losses shift to more ion-dominated with the improved model.

\subsection{Improvement of Confinement}

The effect of the anomalous ion losses on total confinement is about the same in the three tokamaks. The model for anomalous ion losses used in these simulations causes a $15 \%$ reduction in the total energr. confinement time in each of the TFTR. ASDEX. and ALCATOR-C' gas-fuelled cases compary d tu simulations with only neoclassical ion losses. The confinement time in the high density pellet cases is increased up to $40 \%$ (shot 20259) by suppression of the anomalous ion losses atcributed to $\eta$ transport.

As the plasma density is increased. the roles of the electron and ion loss channels change. The trapped-electron diffusivity $x_{e}^{T E} \times \frac{1}{n_{0}}$ decreases with increasing density and becomes less important. Since the $\eta_{1}$ mode diffusivity $x_{1}^{{ }^{k}} \times n_{1}^{-0.6}$, it becomes more important than $x_{r}^{T E}$ with increasing density. The neoclassical $\chi_{2}^{\text {neo }} \times n_{1}$ increases strongly with increasing density and eventually dominates. If the plasma density is peaked relative to the temperature profile so that the $\eta_{1}$ mode is stabilized. the transport losses due to this mode can be minimized. With this picture of transport losses. the maximum confinement time for an experiment with fixed $a, R, Z, B_{Z}$. Ip would 
be found for density high enough to ininimize trapped-electron mode losses but low enough so that nenclassical losses are kept small and with density. profike sufficiently peaked that anomalous ion lusses are suppressed.

Higher confinement will he correlated with minimization of in neoclassical losises as long as anonalous electron and ion losses are also minimized. In the model. $x_{e}^{T E}$ is reduced at high density. Eq. (1). and will be reduced ai the high densities produced by pellet-fuelling. The relative importance of ion neuclassical losses in these three tokamaks can be estimated from the luss parameter $\xi=\frac{n_{\mathrm{e}} \mathrm{a}^{2} \sqrt{\mathrm{a} / \mathrm{k}}}{\sqrt{F}_{\mathrm{F}}^{2}}$. This luss parameter can be obtiined from the

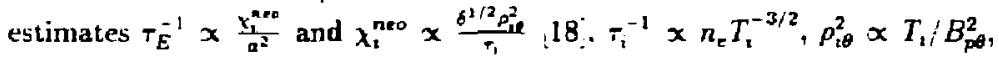
and $B_{\mathrm{p}}^{z} \propto \frac{F_{\mathrm{s}}^{+}}{\mathrm{a}^{4}}$. We can evaluate $\xi$ with the parameters from the pellet phase data in Table $I_{1} I_{P}(M A), R(m), a(m), \pi_{e}\left(10^{19} / m^{3}\right)$. and $T_{i} \sim T_{e}^{e x p}$. Fur these experiments on TFTR. ASDEX. and ALCATOR-C , $\xi=1.3,6.5,1.2$. Comparing $\xi$ among these tokamaks, we see that the TFTR and ALCATOR-C designs minimize neoclassical losses. For the proposed Compact lgnition Tokamak (CIT) $19 ! I_{P}=11$ M.A. $R=2.1 \mathrm{~m}, a=0.65 \mathrm{~m}, n_{\mathrm{c}}=4.5 \times 10^{20} / \mathrm{m}^{3}$, $T_{\mathrm{t}}=20 \mathrm{kel}$, so that $\xi=0.02$. This suggests significantly improved confinement would be seen on CIT, with a suitable pellet injector and divertor to maintain quasi-steady-state peaked density profiles.

\subsection{Particle Transport and Radiation Modeling}

The particle transport models used here, Table VIII, are consistent with the premise that, following pellet injection. limiter and divertor tokamaks exhibit quite different particle transport processes. Experiments on all three tokamaks were simulated with particle transport coefficients which varied inversely as the electron density: These coefficients gave simulated densities which were within $20 \%$ of the measured profiles in the plasma core region. The ratio $v / D$ at the half-radius is shown in Table VIII for the simulations. On ASDEX, $2 / D$ increases by a factor of four following pellet injection and is four times as large as in the simulations of the TFTR or ALCATOR-C experiments.

In pellet experiments on ALCATOR-C 20 particle confinement was found to be correlated with ion energy confinement and not with electron thermal confinement. We found that pellet fuelling at high density was corre- 
lated with reduced ion losses for each tokamak and that the particle transport was improved in that the ratio $" D$ was increased during the pellet phase. Experiments on JET 21 and $A L\left(A T O R-C^{\prime} 20\right.$ indicate that an anomalous inward particle velocity develops for pellet-fuelled discharges. In these simulations although $v / D$ dues increase after pellet injection. neither TFTR nor ALCATOK-C: required a high ratio of anomaleus inward pinch to particle diffusion cuefficient in either gas or pellet-fuelled phases. As in Ref. 22, we modelled ASDEX particle transport with a strong inward pinch during gasfuelling (Table IX). During pellet-fuelling on ASDEX, particle confinement further improves. During the high recycling divertor operation. ASDEX edge recycling is expected $\mathrm{n}$ be less than $30 \%$. TFTK and ALCATOR-C edge recycling was assumed to be $90 \%$.

The functional form of the particle transport coefficients is not prescribed by theory and is not unique. Hulse [2 3 ! has found that a density-dependent diffusion cnefficient is less satisfactory for modelling the postpellet density transport of several TFTH pellet shots than a density-independent model with an $(r / a)^{2}$ dependence. On Jet $: 24 \mid D$ and $v$ are reported not to depend on the density $n_{\mathrm{g}}(r)$ although they do typically increase toward the plasma edge as $(r / a)^{2}$.

If we rewrite the transport coefficients used in this study to be of the form $D \times A \frac{n_{-}(0)}{n_{-}(r)}$ so that near the edge, decreasing density causes an increase in $D$. We find that the coefficient $A$ is $\sim 10^{4}-10^{5} \mathrm{~cm}^{2} / \mathrm{sec}$ for the TFTR and ASDEX cases, as was found for JET. but is higher by an order of magnitude for the ALCATOR-C simulations. Data from JET indicate that $D$ may be intersely proportional to $I_{P}$ :24:- If we rewrite

$$
D \propto B \frac{n_{e}(0)}{n_{e}(r) l_{p}}
$$

we find that the TFTR and ASDEX cases are modelled by $B \sim 10^{4}-$ $10^{5} \mathrm{~cm}^{2} /(\mathrm{sec}-M A)$ but that for the ALCATOR-C cases. $B$ is again an order of magnitude higher. We propose that $\mathrm{Eq}$. (i) roughly describes particle transport in the plasma core of large tukamaks. In smaller tukamaks where edge fuelling and scrape-off loss effects are of more importance. the core particle transport mudel would have tu be modified.

A comparison of the Ware pinch and the anomalous pinch effects in the simulations is shown in Table $\mathbb{X}$. In the TFTK simulation, at the half-radius 
we find the anomalous and nenclassical pinch velocitiss to be small. less than $6 \mathrm{~cm}$ : sec. Hulse 23 has successfully modelled TF"TR pellet shots with A.MUV : O). We find that the ALCATOR-C' simulations show a larger Ware pinch (12 -20 cm: sec). The anomalous pinch is only 1,3 to 1 is of the nes. classical pinch for these cases. The ASDEX simulations were also found to shum large Hare pinch $(10-20 \mathrm{~cm} / \mathrm{sec})$ and here the anomalous pinch is large and comparable to the neuclassical pinch at the half-radius.

In the gas phase, the three tokamaks have similar impurity and bremsstrahlung radiation, $P_{\text {rad }} / P_{O H}<35 \%$. The TFTR pellet case had significantly greater radiation losses. The effect of the variation in radiated power among these experiments has been included in the total heating power dependence of the models.

For the TFTR cases, the electron temperature calculation is not sensitive to the details of the density profile since electron conduction losses are dominant and $n_{e} \chi_{e}$ is used in the calculation. not $\chi_{e}$ atone. For the other simulations. where ion losses dominate the power balance, the eflect of an imperfect match of the density profile to experimental data becomes more important.

As nuted in Section 2. the model was derived under the assumption of steady-state conditions for plasma current, densities, and temperatures. The model, being hased on an assumption of ohmic equilibrium, is not valid for current ramp cases. We have found inverse correlation between the accuracy of $\tau_{E}$ predicted and the percent density change over a confinement time. The ASDEX gas-fuelled and the ALCATOR-C and TFTR pellet-fuelled simulations exhibit a change in the line average density of less than $10-20 \%$ over a continement time. and are not far from ohmic equilibrium. The density variation in these simulations is seen to cause the confinement and electron temperature predictions to be less than $30 \%$ in error. This should be compared to the less than $\mathbf{2 0 \%}$ error found in the quasi-constant density cases: the ASDEX pellet-fuelled cases, the TFTR and ALCATOR-C' gas puff cases. as well as the TFTR gas puff cases studied earlier 20 .

\subsection{Comparison of Measured and Simulated Neutron Rates}

In Table $X$ are presented the simulated and measured neutron rates for the TFTH and ALCATOR-C' experiments. The ubserved trend of increased 
neutron rate with incteased density via pellet fuelling is seen also in the simulations. The ALC'ATOR-(' data are werestimated by a factor of 4 and the TFTH data are werestimated by a factor "f $t-6$ by the simulations. The sirmulations" wertstimate of the neutron rates may be due either tu the simulated ion temperature profiles being broader than the actual ion temperature profiles. or 10 the simulated plasma temperatures being higher than in the experiments. The D.D neutron rate calculation is a sensitive function of temperature. If the electron and jun temperatures are raised I0from 1.9 hel to 2.2 kel for shot 20259 , for example, the predicted neut ron rate is increased a factur of 2 . ffom $1.2 \times 10^{1-1}$ neutrons sec $^{2}$ to $2.1 \times 10^{14}$ neutrons/sec. The measured neutron rates are accurate to within about a Fatur of 2 . It appears that the musdel systematically overestimates the ion temperatures by $10 \%$ to $20 \%$. Whether this is because of an overall scaling and 'or a profile effect can only be determined when the model predictions can be compared with measured ion temperature profiles.

\section{SUMMARY}

The microinstability-based models for $x_{e}$ and $x_{1}$ have been used for simulation of gas and pellet-fuelled discharges on the TFTR. ASDEX. and ALC ATOH-C lwkamaks. The TFTR calibration of the model gives reasonahle asreenun with measured temperature profiles and confinement times fur both gas and pellet-fuelled ohmic discharges on these machines for quasisteady-statc conditions. It was found that the trapped electron and $\eta_{t}$-ctriven transport models were consistent with the experimentally obsermed confinement of gas-fuelled discharges and that suppression of $\eta_{i}$-driven transport could account for significantly improved energy confinement in pellet-fuelled discharges on the TFTR. ASDEX. and ALCATOR-C tokamaks.

The model has recently been found to produce correlation betveen observed plasma fluctuation signals and significant $\eta_{t}$-driven anomalous ion losses 25.26. A detailed comparison of the model diffusivities to thuse derived [rom the measurements of elect ron and inn temperature profiles will be an important future test of this therry. 


\section{ACKNOWLEDGMENTS}

Wi uratefully acknowledgo the physicist: whose measurements "f TFTli. ASLEX. and ALC ATOR-C experimentai dala made possible these simula. tiuns. The authors especially wish to thank F. Hagner for his interest in the simulations of the ASDEX pellet data and F. Mast. R. Muller. A. Eberhagen. 1) Gehre. H. Murmann. K.-H. Steuer. and K. Lang. plasma diagnosticians for the ASDEX pellet stoots. We are als" glad t" acknowledge valuable con. versations with D. R. Mikkelsen, G. L. Schmidt, and D. Stotler.

This work was supported b: L.S. Department of Energy Cintract Nio. DE-AC:02-i6-C:HO-3073. 


\section{REFERENCES}

1 W'. M. Tang "Microinstability-Based Model for Anumalous Thermal ('onlinement in Tukamaks." Vucl. Fusion 26 (1981i)1605.

22 M. H. Kedi. WI. M. Tang. P. C. Efthimion. D. K. Mlikkelsen. and C. L. Schmidt. "Transport Simulations of Ohmir TFTR Experiments with Profile.

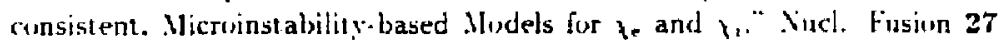
$(198 \pi) \geq 001$.

3 IV. M. Tang, ('. M. Bishop, B. Coppi, S. M. Kaye. F. M. Perkins. II. H. Redi, and G. Rewoldt. "Microinstability-Based Mludels for Confinement Properties and Ignition Criterion in Tokamaks."Proc. Il th Int. Conf. Plasma Physics and Controlled Nuclear Fusion. Kyoto. Japan. November 13-20 1986, IAEA-CN-4T/A-VI-1-2.

4 D. L. Brower. W. A. Peebles, S. K. Kim, and N. C. Luhmann, Jr.. W. II. Tang and P. E. Phillips. "Observation of a High-Density Ion Mlode in Tokamak Microturbulence." Phys. Kev. Lett. 59 (1987) 48.

j' G. A. Hallock, W. J. Wooten, R. L. Hickok, "Space Potential and Density Fluctuations in the ISX-B Tokanak," Phys. Rev. Lett. 59 (1987)1301.

6 (C. E. Singer. D. E. Post. D. R. Mikkeisen, M. H. Redi. A. McKenney et al. "BALDI'R: A One-Dimensional Plasma Transpurt Cide." to be published in Computer Phys. Commun. (1988).

T M. Cireenwald. D. Gwinn. S. Milora. J. Parker. K. Parker. et al. -Energy (onfinement of High-Density Pellet-Fuelled Plasmas in the ALCATOR(" Tokamak." Phy.s. Kev. Lett. $\mathbf{5 3} \div$ (1984) 352.

8 .II. Greenwald. D. Gwinn. S. Milora. J. Parker, R. Parker. et al.. "Pellet Fuelling Experiments in ALCATOR-C. " IAEA-CX-4t A-1-3! London. 1084!

9 G. L. Schmidt, S. L. Milora, V. Arunasalam, M. G. Bell. M. Bitter, et al. "Pellet Injection Results during TFTR Ohmic and Neutral Beam Heating Experiments." IAEA-CN-4Z/A-III-4 (Kyoto, 1986).

:10!. G. Vlases. O. Gruber, M. Kaufmann. K. Buchl. (i. Haas, et al.. "Quasi-stationary Pellet Fuelled Ohmic Discharges with Medium Density. in ASDEX." Nucl. Fusion 27 (1987)351.

11 . Milora. S. L, Foster, C. A.. "ORNL Nentral Gas Shielding Model for Pellet-Plasma Interactions," Rep. ORNL-TM-5776. Oak Kidge National Laburatory. Oak Ridge. TN (1977). 
12. Houlberg. 14. A. Iskra, M. A. Howe. H. ('. Attenberger, S.. "PEL. LET - A Compuer Koutine for Mudeling Fellet Fueling in Tokamak Plas-

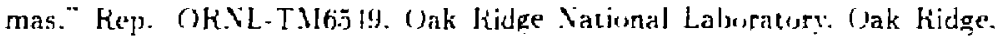
TX(1979).

13 M. C. Zarnsiorff. M. G.Bell. M. Bitter. (". Bush. K. J. Funck. d. - "Convertive Heat Transport in TFTH Supershots." Eur. Phrs. Sric. Dubrovitik. 1988.

It R. J. Groebner et al. Nucl. Fusion 26 (1986)ǰt4.

15 K. J. Fonck. M. Bitter, R. Goldston. R. Howell. H. Hsuan. et al. . "Ion Temperature Profiles and lon Thermal Confinement in TFTK." EPS. Dubrounik (1988).

16 k. J. Fnnck. "lon Power Balance and Rotation Studies in Yeutral Beam Heated Plasmas in TFTR." Bull. Am. Phys. Soc. 32 (198i) $18+6$.

17 5. M. Wolfe. M. Greenwald. Fl Gandy. R. Granetz, et al.."Effect of Pellet Fuelling on Energy Transport in Ohmically Heated ALC'ATOR-C' Plasmas." Xucl. Fusion 26 (1986) 329.

18 F. L. Hinton. F. D. Hazeltine. Fers. Mod. Phys. 48 (1976)239.

Ig R. R. Parker. and CIT Giroup. "CIT Phisics Basis and Periormance Analysis." (AE A (Cadarache. France) I488. to be published.

20 .1. Ciremald. M. Besen. F. (anacho. C. Fiore. M. Ford. al d. "Studies of the Regime of Improved Barticle and Energy" Confinemert following Pellet Injertion into ALCATOK-C' ." IAEA-C:S-AT/A-III-1, (Kyoto, 1936).

2l A. Gondhalekar, A. C'heetham. N. Bures. D. Campbell. S. A. Cohen. et al. "Pellet Fueling of Jet Plasmas during Ohmic. ICRF and NBI Heating," IAEA-CX-4i;I-I-6 (Kyoto. 1986).

22 M. Kaufmann. K. Buchl, G. Fussmann. O. Gehre. K. Grassie. $t$ t al. "Pellet Injection with Improved Confinement in ASDEX." Nucl. Fusion 28 ( 1988 ) $82 \bar{i}-848$.

23 F. A. Hulse. P. Efthimion. B. Cirek. K. Hill, D. Johnson. el al. . "Particke Transport in TFTR Ohmic Pellet Injection Experiments." Eur. Phys. Soc. (Madrid) 1987. 318.

24. A. Cundalakar. A. Cheetham, S. A. Coben, W: Houlberg, T. C. Jones. ctal.. "Control of Density. Profile for Optimization of $Q_{n T}$ in JET." Buil. Anr. Phys. Suc. 321838 (1987).

25 D. L. Brower. S. K. Kim. II. M. Tang. M. H. Kedi. M. E. Austin. $\epsilon t$ al. 
"Experimental Observation of Ion Temperature Ciradient Driven Turbulence in the TEXT Tokamak" Eur. Phrs. Suc. (Jubrownik) 1988.

26 .1. Il. Kedi. W. M. Tang. D. L. Brower. and P. C. Efthimisn. "Trans. port Simulations of Ohrnic and EC'RH Heated Experiments on TFTR. T-10 and TEXT." Sherwoud Theory ('unference (1988). 
TABl.E 1. Simulation Inpul Parantelers

\begin{tabular}{|c|c|c|c|c|c|c|c|c|c|}
\hline & SHOT & $I_{P}(H A)$ & $B_{i}(T)$ & $n(m)$ & $a(m)$ & $\bar{n}_{c}\left(10^{19} / m^{3}\right)$ & $P_{\text {rad }} / P_{\mathrm{OH}}$ & $2_{\text {eff }}$ & $q_{a}$ \\
\hline \multirow[t]{3}{*}{ TFTB } & 18681 & 1.6 & 5.2 & 2.4 & 0.72 & $3.4(13.0):$ & 0.65 & $1.6(1.2) *$ & 3.4 \\
\hline & 18673 & 1.6 & 5.0 & 2.4 & 0.72 & 3.4 & 0.27 & 2.0 & 3.4 \\
\hline & 20259 & 1.6 & 4.9 & 2.4 & 0.71 & $14.1 *$ & 0.65 & 1.8 & 3.3 \\
\hline \multirow[t]{2}{*}{ ASDEX } & 18876 & 0.38 & 2.17 & 1.6 & 0.4 & $3.5(9.3):$ & $0.2-0.4$ & 1.1 & 2.8 \\
\hline & 18716 & 0.38 & 2.17 & 1.6 & 0.4 & $3.8(9.5)$ & $0.2-0.4$ & 1.1 & 2.8 \\
\hline \multirow[t]{2}{*}{ ALCATOR } & 80 & $0.38(0.36)=$ & 8.1 & 0.64 & 0.16 & $18 .(28):=$ & 0.35 & $1.2(1.1) \div$ & $4.5(4.8):$ \\
\hline & 62 & 0.78 & 11.3 & 0.64 & 0.16 & $30 .(70 .)^{6}$ & 0.35 & $1.1(1.0)^{\frac{1}{n}}$ & 3.1 \\
\hline
\end{tabular}

*after pellet injection 
TABLE II.

Comparison of TETR Simulations and Experiments

\begin{tabular}{|c|c|c|c|c|}
\hline & Gas & Fueled & 3 Pellets & $(2.8 \mathrm{sec})$ \\
\hline & $\underline{\text { SISI }}$ & ExP & $\underline{S I M}$ & $\underline{\operatorname{EXP}}$ \\
\hline$\tau_{E}(\sec )$ & 0.28 & $0.29+0.03$ & $0.36 \%$ & $0.32+0.03 *$ \\
\hline$T_{e}(0)(\mathrm{Kev})$ & 2.9 & 2.9 & 1.9 & 1.4 \\
\hline$n_{e}(0)\left(10^{20} / m^{3}\right)$ & 0.47 & 0.45 & 2.9 & 2.6 \\
\hline$v_{\text {loop }}(v)$ & 0.9 & 0.8 & 1.2 & 1.3 \\
\hline$\nu_{* e}(q-1.5)$ & 0.2 & & 0.7 & \\
\hline$\eta_{\mathbf{i}}$ & 3,0 & & 1.5 & \\
\hline
\end{tabular}


TABLE III.

Comparison of ASDEX Simulations and Experiments Shot 18876 (17 Pellets)

\begin{tabular}{|c|c|c|c|c|}
\hline & \multicolumn{2}{|c|}{$\begin{array}{l}\text { Gas Phase } \\
1.0 \text { sec }\end{array}$} & \multicolumn{2}{|c|}{$\begin{array}{c}\text { Pellet Phase } \\
2.0 \mathrm{sec}\end{array}$} \\
\hline & $\underline{S I M}$ & $\underline{\operatorname{EXP}}$ & $\underline{S I M}$ & $\underline{\mathrm{EXP}}$ \\
\hline$T_{E}(\sec )$ & 0.07 & 0.03 & 0.14 & 0.15 \\
\hline$T_{e}(0)(k e V)$ & 1.0 & 0.77 & 0.74 & 0.70 \\
\hline $\mathrm{n}_{\mathrm{e}}(0)\left(10^{19} / \mathrm{m}^{3}\right)$ & 5.2 & 5.1 & 16.0 & 16.0 \\
\hline$v_{10 o p}(v)$ & 2.5 & & 1.2 & \\
\hline$\nu_{* 2}(q-1.5)$ & 1.8 & & 1.2 & \\
\hline$\eta_{i}$ & 2.9 & & 0.3 & \\
\hline
\end{tabular}

Shot 18716 (11 Pellets)

\begin{tabular}{|c|c|c|c|c|}
\hline & \multicolumn{2}{|c|}{$\begin{array}{c}\text { Gas Phase } \\
1.4 \mathrm{sec}\end{array}$} & \multicolumn{2}{|c|}{$\begin{array}{l}\text { Pellet Phase } \\
1.8 \mathrm{sec}\end{array}$} \\
\hline & $\underline{\text { SIM }}$ & $\underline{\operatorname{EXP}}$ & $\underline{\text { SIM }}$ & $\underline{\text { EXP }}$ \\
\hline${ }^{t} E^{(0)}$ & 0.08 & 0.09 & 0.17 & 0.15 \\
\hline$T_{e}(0)$ & 0.92 & 0.76 & 0.58 & 0.58 \\
\hline$n_{e}(0)$ & r. 3 & 6.0 & 20 & 20 \\
\hline$v_{\text {loop }}$ & 1.4 & 1.2 & 1.6 & 1.5 \\
\hline$\nu_{* e}$ & 2.3 & $>1$ & 5.1 & $>4$. \\
\hline$\eta_{i}$ & 3.5 & $2 .-3$ & 1.0 & $0.2-1$ \\
\hline
\end{tabular}


TABLE IV.

Comparison of ALCATOR Simulations and Experiments

\begin{tabular}{|c|c|c|c|c|c|c|}
\hline \multirow{3}{*}{ SHOT 80} & \multirow{2}{*}{\multicolumn{2}{|c|}{$\begin{array}{l}\text { Prepellet } \\
\varepsilon=0.200 \mathrm{~s}\end{array}$}} & \multicolumn{4}{|c|}{ Post-Pellet } \\
\hline & & & \multicolumn{2}{|c|}{$=-0.350 \mathrm{~s}$} & \multicolumn{2}{|c|}{$t=0.400 \mathrm{~s}$} \\
\hline & $\underline{\text { SIM }}$ & $\underline{E P}$ & SIII & EXP & $\underline{S I M}$ & $\underline{E X Z}$ \\
\hline$r_{E}(\sec )$ & 0.035 & 0.030 & 0.028 & 0.030 & 0.042 & 0.028 \\
\hline $\mathrm{T}_{\mathrm{e}}(0)(\mathrm{keV})$ & 1.9 & 1.8 & 1.2 & 1.3 & 1.5 & 1.3 \\
\hline$n_{e}(0)\left(10^{20} / \mathrm{m}^{3}\right)$ & 2.7 & 2.8 & 5.0 & 5.0 & 4.8 & 4.5 \\
\hline$v_{100 p}(v)$ & I. 3 & 1.8 & 1.9 & 2.0 & 1.5 & 2.0 \\
\hline$\nu_{\text {:e }}(q-1,5)$ & 0.6 & & 2.8 & & 1.2 & \\
\hline \multirow[t]{2}{*}{$\eta_{i}$} & 1.6 & & 1.5 & & 2.0 & \\
\hline & \multicolumn{2}{|c|}{ Post-Pellet } & & & & \\
\hline \multirow[t]{2}{*}{ SHOT 62} & \multicolumn{2}{|c|}{$I=0.53 \mathrm{~s}$} & & & & \\
\hline & IIII & $\underline{\text { EXP }}$ & & & & \\
\hline$\tau_{E}$ & 0.054 & 0.048 & & & & \\
\hline$T_{2}(0)$ & 1.5 & 1.5 & & & & \\
\hline$n_{e}(0)$ & 6.0 & 16 & & & & \\
\hline$v_{\text {loop }}$ & 2.0 & $2.0+0.3$ & & & & \\
\hline$\nu_{* e}$ & 1.3 & & & & & \\
\hline$\eta_{i}$ & 0.4 & & & & & \\
\hline
\end{tabular}


TABLE $V$.

Comparison of $T_{e}$ and $t \equiv$ Eor Several Ion Diffusiviz:

Aodels foz alcaior Cases

SHOT 80

\begin{tabular}{|c|c|c|c|c|}
\hline \multirow[b]{2}{*}{ :OODEL } & \multicolumn{2}{|c|}{ Prepelle: } & \multicolumn{2}{|c|}{ Post-pellet $(t=0.35 \mathrm{sec})$} \\
\hline & $\tau_{\mathrm{e}}(\mathrm{keV})$ & $\left.{ }^{\tau_{E}}(\sec \rangle\right)$ & $I_{\mathrm{e}}(\mathrm{keV}\rangle$ & $\tau_{E}(\sec )$ \\
\hline$\eta_{i}$ & 1.9 & 0.035 & 1.2 & 0.028 \\
\hline $4 x^{\mathrm{CH}}$ & 1.6 & 0.040 & 1.1 & 0.030 \\
\hline $2 x^{\mathrm{CH}}$ & 2.0 & 0.064 & 1.5 & 0.057 \\
\hline $\mathrm{I}_{x} \mathrm{CH}$ & 2.5 & 0.102 & 2.1 & 0.088 \\
\hline Exp & 1.8 & 0.030 & 1.3 & 0.030 \\
\hline
\end{tabular}

SHOT $5 ?$

\begin{tabular}{lll} 
& \multicolumn{2}{c}{ Post-Pellet } \\
YODEL. & $T_{e}(\mathrm{keV})$ & $T_{E}(\mathrm{sec})$ \\
\hline$\pi_{i}$ & 1.5 & 0.054 \\
$4 x^{\mathrm{CH}}$ & 1.1 & 0.039 \\
$2 x^{\mathrm{CH}}$ & 1.3 & 0.048 \\
$1 \chi^{\mathrm{CH}}$ & 1.5 & 0.056 \\
$\mathrm{Exp}$ & 1.5 & 0.048 \\
\hline
\end{tabular}


TABLE VI.

Energy Losses at a/2 - lleating Species Dependent Hodel

\begin{tabular}{|c|c|c|c|c|c|c|c|c|c|c|}
\hline & $\begin{array}{l}\mathrm{T}_{\mathrm{e}}(0) \\
(\mathrm{KeV})\end{array}$ & $\begin{array}{l}T_{i}(0) \\
(\mathrm{KeV})\end{array}$ & $\begin{array}{l}Q_{e}^{\text {cond }} \\
(H H)\end{array}$ & $\begin{array}{l}Q_{i}^{\text {cond }} \\
(H W)\end{array}$ & $\begin{array}{l}P_{\text {rad }} \\
\text { (HN) }\end{array}$ & $\begin{array}{l}\mathbf{P}_{0 ! 1} \\
(1 W W)\end{array}$ & $\begin{array}{l}Q_{e i} \\
(H W)\end{array}$ & $\begin{array}{l}{ }^{\top} \mathrm{eE} \\
\text { (sec) }\end{array}$ & $\begin{array}{l}{ }^{\tau} \text { iE } \\
\text { (sec) }\end{array}$ & $\begin{array}{l}{ }^{\mathrm{T}} \mathrm{E} \\
(\mathrm{sec})\end{array}$ \\
\hline \multicolumn{11}{|l|}{ IETR } \\
\hline gas & 2.9 & 2.5 & 0.51 & 0.10 & 0.09 & 0.12 & 0.11 & 0.20 & 0.48 & 0.28 \\
\hline \multicolumn{11}{|c|}{ Shot 18681} \\
\hline pellet & 1.9 & 1.8 & 0.76 & 0.08 & 0.26 & 1.17 & 0.12 & 0.24 & 1.20 & 0.40 \\
\hline \multicolumn{11}{|l|}{$\underline{A S D E X}$} \\
\hline gas & 1.0 & 0.8 & 0.10 & 0.12 & 0.03 & 0.27 & 0.13 & 0.070 & 0.077 & 0.073 \\
\hline pellet & 0.7 & 0.7 & 0.06 & 0.09 & 0.05 & 0.26 & 0.12 & 0.081 & 0.499 & 0.138 \\
\hline \multicolumn{11}{|l|}{ ALCATOR } \\
\hline \multicolumn{11}{|l|}{ Shot 80} \\
\hline gas & 1.9 & 1.3 & 0.14 & 0.14 & 0.04 & 0.31 & 0.14 & 0.030 & 0.044 & 0.035 \\
\hline pellet & 1.2 & 1.0 & 0.06 & 0.28 & 0.05 & 0.43 & 0.30 & 0.023 & 0,038 & 0.028 \\
\hline \multicolumn{11}{|l|}{ Shot 62} \\
\hline pellet & 1.5 & 1.4 & 0.26 & 0.20 & 0.19 & 0.89 & 0.33 & 0.034 & 0.141 & 0.054 \\
\hline
\end{tabular}


TABLE VII.

Energy Losses at a/2 - Total lleating Dependent Model

\begin{tabular}{|c|c|c|c|c|c|c|c|c|c|c|}
\hline & $\begin{array}{l}T_{e}(0) \\
(\mathrm{KeV})\end{array}$ & $\begin{array}{l}T_{j}(0) \\
(K \in V)\end{array}$ & $\begin{array}{l}Q_{\mathbf{E}}^{\text {cond }} \\
(\mathrm{HW})\end{array}$ & $\begin{array}{l}Q_{i}^{\text {cond }} \\
(\mathrm{HW})\end{array}$ & $\begin{array}{l}P_{\mathrm{rad}} \\
(N W)\end{array}$ & $\begin{array}{l}P_{\mathrm{OH}} \\
(\mathrm{HW})\end{array}$ & $\begin{array}{l}Q_{e i} \\
(H W)\end{array}$ & $\begin{array}{l}\mathrm{t}_{\mathrm{eE}} \\
(\sec )\end{array}$ & $\begin{array}{l}T_{i E} \\
(\mathrm{sec})\end{array}$ & $\begin{array}{l}\mathbf{T}_{\mathbf{E}} \\
(\sec )\end{array}$ \\
\hline \multicolumn{11}{|l|}{ TFTR } \\
\hline gas & 3.0 & 2.6 & 0.60 & 0.11 & 0.13 & 0.86 & 0.12 & 0.20 & 0.59 & 0.29 \\
\hline \multicolumn{11}{|c|}{ Shot 18681} \\
\hline pellet & 1.7 & 1.7 & 0.74 & 0.08 & 0.26 & 1.20 & 0.14 & 0.23 & 1.16 & 0.38 \\
\hline \multicolumn{11}{|l|}{ ASDEX } \\
\hline gas & 1.0 & 0.83 & 0.15 & 0.07 & 0.03 & 0.27 & $0.0 \mathrm{~B}$ & 0.059 & 0.086 & 0.069 \\
\hline pellet & 0.6 & 0.6 & 0.09 & 0.07 & 0.06 & 0.28 & 0.10 & 0.064 & 0.482 & 0.112 \\
\hline \multicolumn{11}{|c|}{ ALCATOR } \\
\hline \multicolumn{11}{|c|}{ Shot 80} \\
\hline gas & 1.8 & 1.4 & 0.18 & 0.10 & 0.04 & 0.31 & 0.09 & 0.023 & 0.068 & 0.034 \\
\hline pellet & 1.2 & 1.0 & 0.16 & 0.18 & 0.05 & 0.43 & 0.19 & 0.021 & 0.131 & 0.036 \\
\hline \multicolumn{11}{|c|}{ Shoc 62} \\
\hline pelliet & 1.4 & {$[.3$} & 0.33 & 0.17 & 0.19 & 0.91 & 0.29 & 0.030 & 0.130 & 0.048 \\
\hline
\end{tabular}


TABLE VIII.

Enpizical garticle Transport Sodels

$$
\begin{aligned}
& D=D^{\text {AHON }}+D_{\text {NEO }} \\
& v=v^{\text {ANOM }}+v^{\text {Hare }}
\end{aligned}
$$

\begin{tabular}{|c|c|c|c|}
\hline Recycling & $\begin{array}{c}D^{\text {ALYM }} \propto\left\{1 / n_{3}\left(10^{20} / m^{3}\right)\right\} \\
\left(m^{2} / \sec \right)\end{array}$ & $\begin{array}{c}\text { जAHOM } \propto(\mathrm{r} ; \mathrm{a})\left[1 / \mathrm{n}_{\mathrm{e}}\left(10^{20} \mathrm{~m}^{3}\right)\right\} \\
(\mathrm{m} / \mathrm{sec})\end{array}$ & $\begin{array}{l}y / 01:=a / 2 \\
i m-i\end{array}$ \\
\hline
\end{tabular}

\section{TETR}

$\begin{array}{lllll}\text { jas } & 0.9 & 0.04 & 0.025 & 0.3 \\ \text { Fe!let } & 0.9 & 0.03 & 0.045 & 0.3\end{array}$

$\stackrel{\text { SDEX }}{ }$

$\begin{array}{lllll}\text { jas } & 0.3 & 0.1 & 0.2 & 1.0 \\ \text { peliee } & 0.3 & 0.05 & 0.4 & 4.0\end{array}$

\section{S.LCATOR}

$\begin{array}{lllll}\text { Sas } & 0.9 & 0.08 & 0.15-0.20 & 1.2 \\ \text { pellee } & 0.9 & 0.1-0.2 & 0.30 & 1.3\end{array}$

Energy of

recycled

neutrals

$20-40 \mathrm{eV}$ 
TABLE IX.

Anomalous and Neoclassical Pinch Results from Simulaciors

\begin{tabular}{|c|c|c|c|c|}
\hline & & $v_{(a / 2)}$ & $v_{(a / 2)}^{W A R E}$ & $\nabla^{A N O H} / \nu^{N(N R E}(a / 2)$ \\
\hline \multirow[t]{2}{*}{ TFTR } & gas & $3.4 \mathrm{~cm} / \mathrm{s}$ & $5.5 \mathrm{~cm} / \mathrm{sec}$ & 0.7 \\
\hline & pellet & 3.0 & 5.2 & 0.5 \\
\hline \multirow[t]{6}{*}{ ASDEX } & Shot 18716 & & & \\
\hline & gas & 20 & 18. & 0.9 \\
\hline & pellet & 16 & 9.5 & 2 \\
\hline & Shot $188: 6$ & & & \\
\hline & gas & 22 & 20 & 1 \\
\hline & peliet & $\$ 4$ & 13. & 1 \\
\hline \multirow[t]{6}{*}{ ALCATOR } & Shot 80 & & & \\
\hline & gas & 3.7 & 19. & 0.2 \\
\hline & pellet & 4.6 & 16. & 0.3 \\
\hline & Shor 62 & & & \\
\hline & gas & $\cdots$ & $\cdots$ & $\cdots$ \\
\hline & pellet & 2.2 & 12. & 0.2 \\
\hline
\end{tabular}


TABLE $\mathrm{X}$.

DD Neutron Rate

\begin{tabular}{lll}
\hline & DATA & SIMULATION \\
\hline TFTR & & \\
18673 & $0.36 \times 10^{13} \mathrm{n} / \mathrm{s}^{*}$ & $1.5 \times 10^{13} \mathrm{n} / \mathrm{s}$ \\
18681 & $1.0 *$ & $6.2 \times 10^{13}$ \\
20259 & $2.5 *$ & $1.2 \times 10^{14}$ \\
& & \\
ALCATOR-C & & $3.4 \times 10^{11}$ \\
80 (gas phase) & $1.0 \times 10^{11}$ & $7.3 \times 10^{11}$ \\
80 (pellet phase) & $3.4 \times 10^{11}$ & $2.3 \times 10^{13}$ \\
62 & $5.5 \times 10^{12}$ & \\
\hline
\end{tabular}

*Accurate to $+50 \% /-358$ 


\section{Figure Captions}

1a. TFIK temperature profiles for gas puff shut 156 it3 compared to simulation resukts.

1b. TFTK density profiles fur gas puff shut 18673 compared to simulation results.

2a. TFT fi temperature profiles for pellet shot 18681 compared to simulation results.

2b. TFTK density profiles for pellet shot 18681 compared to simulation results.

3. Line averaged electron density time evolution for ASDEX shut 18876.

ta. ASDEX temperature profiles for gas phase 18876 compared to simulation results.

4h. ASDEX density profiles for gas phase 18876 compared to simulation result s.

5a. ASDEX temperature profiles for pellet phase 18876 compared to simulation results.

5b. ASDEX density profiles for pellet phase 18876 compared to simulation results.

6a. ASDEX temperalure profiles for gas phase shot 18716 compared to simulation resuits.

61. ASDEX density profiles for gas phase shot $18 \pi 16$ compared to simulation results.

ia. ASDEX temperature profiles for pellet phase shot 18716 compared to simulation results.

ib. ASDEX density profites for pellet phase shot 18716 compared to simulation results.

$8 a \chi_{e}$ from simulation of ASDEX gas and pellet phases for shot $18: 16$.

$8 \mathrm{~b} \chi_{\mathrm{z}}$ from simulation of ASDEX gas and pellet phases for shot $18 \mathrm{i} 16$.

9a. ALC'ATOR-C' temperature profiles for gas phase shot 80 compared to simulation results.

9b. ALCATOR-C density profiles for gas phase shot 80 cumpared to simulation results.

10a. ALCATOR-C temperature profiles for pellet phase shot 80 compared to simulation results. 
10b. ALCATOR-C' density profiles for pellet phase shot 80 compared to simulation results.

I la. ALCATOR-(' temperature profiles fur pellet shost $6^{\circ}$ ?

l b. ALC ATOK-C density profiles for pellet shot 62 compared to simu. lation results. 

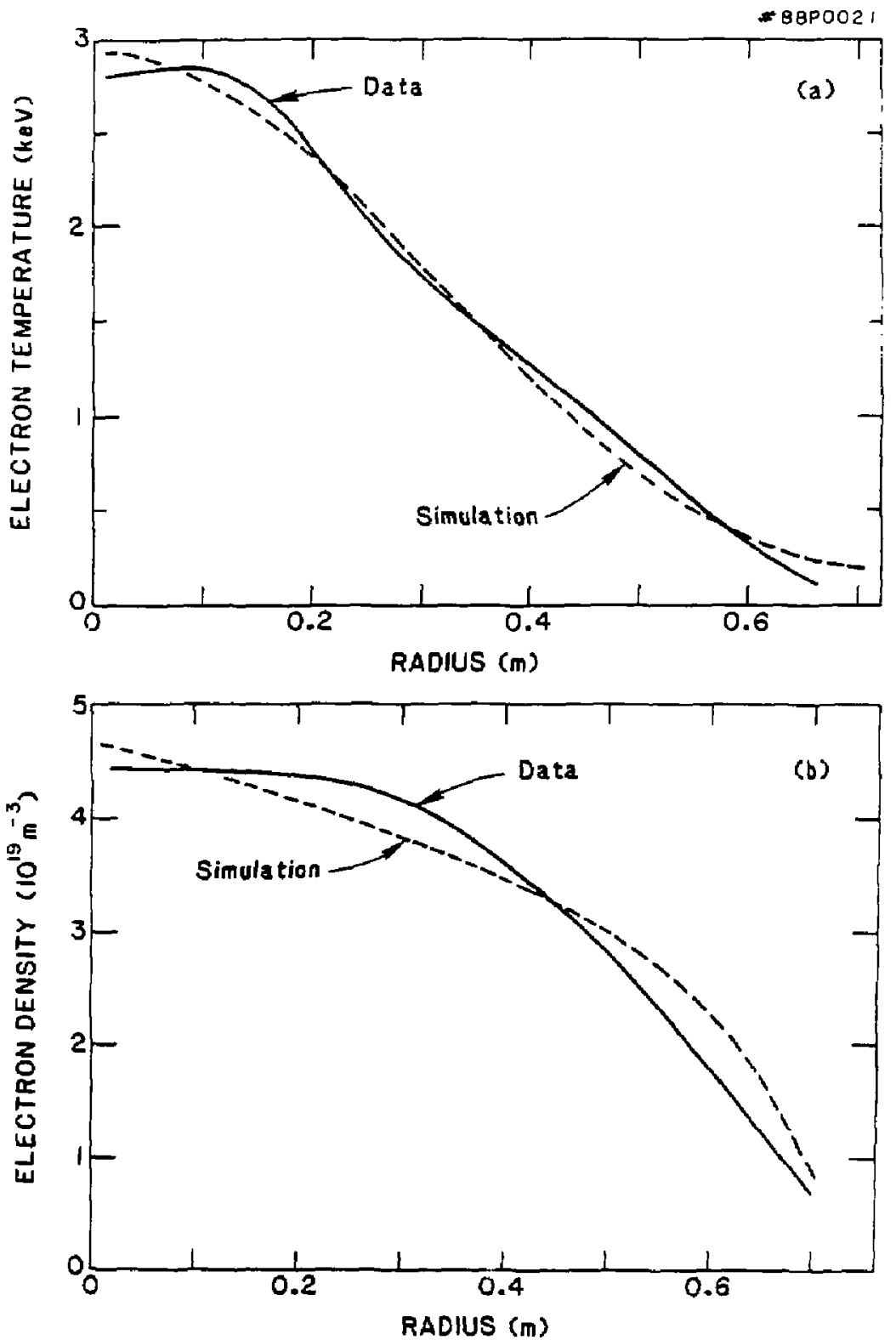

FIG. 1 

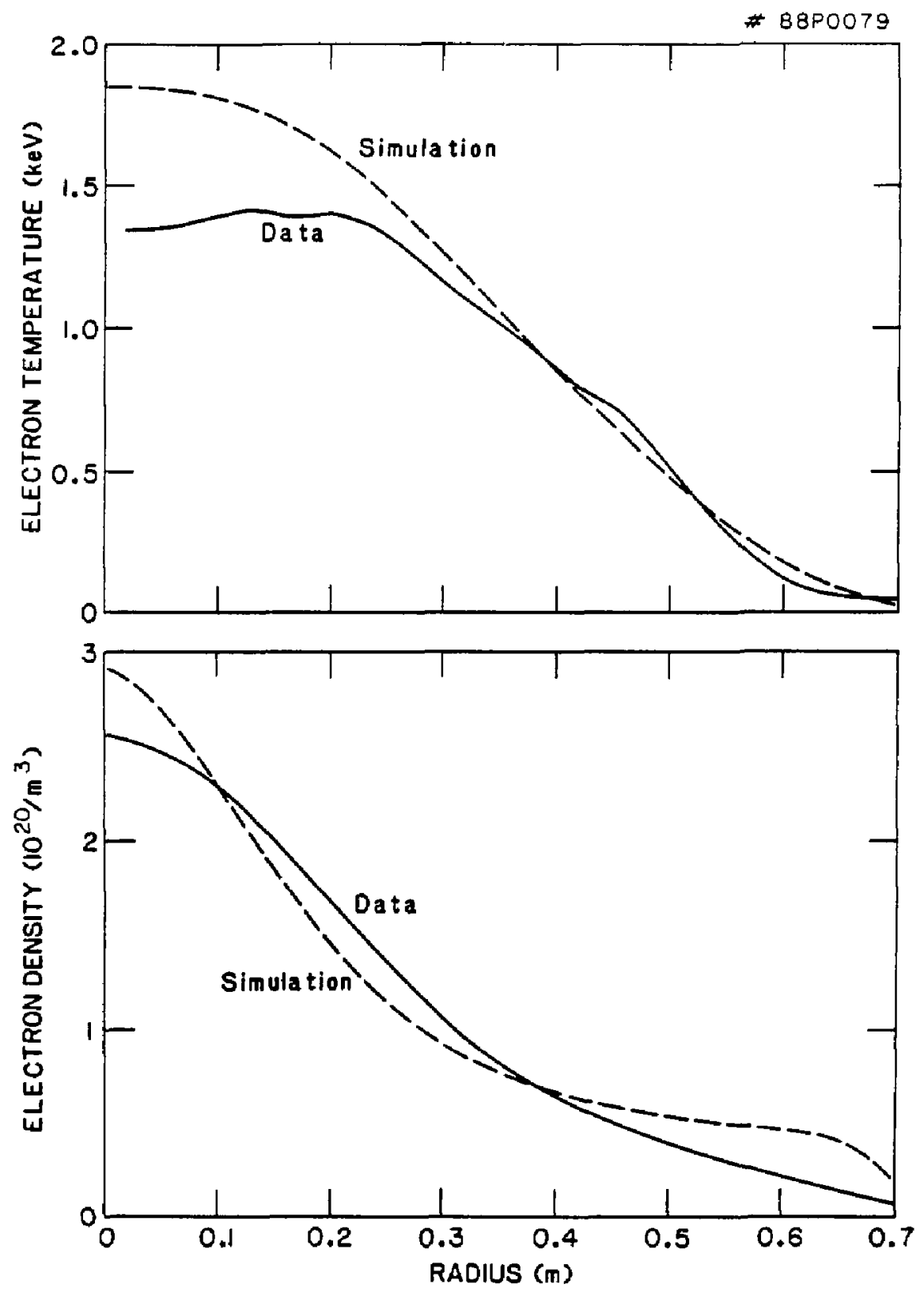

FIG. 2 
\# 87P0038

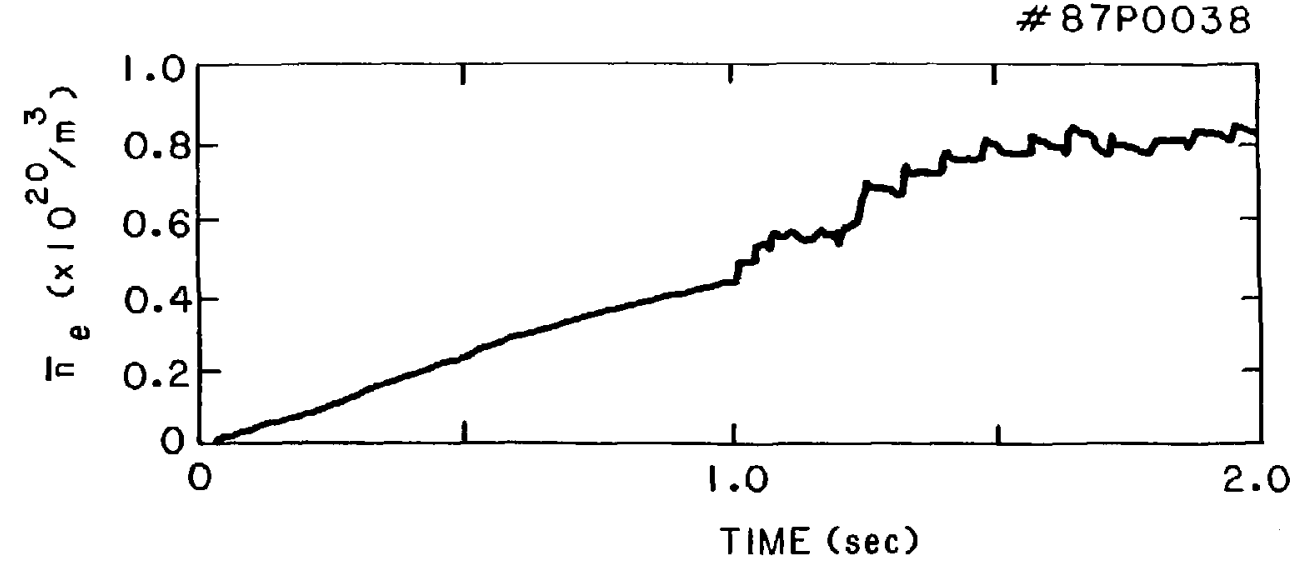

FIf. 3 

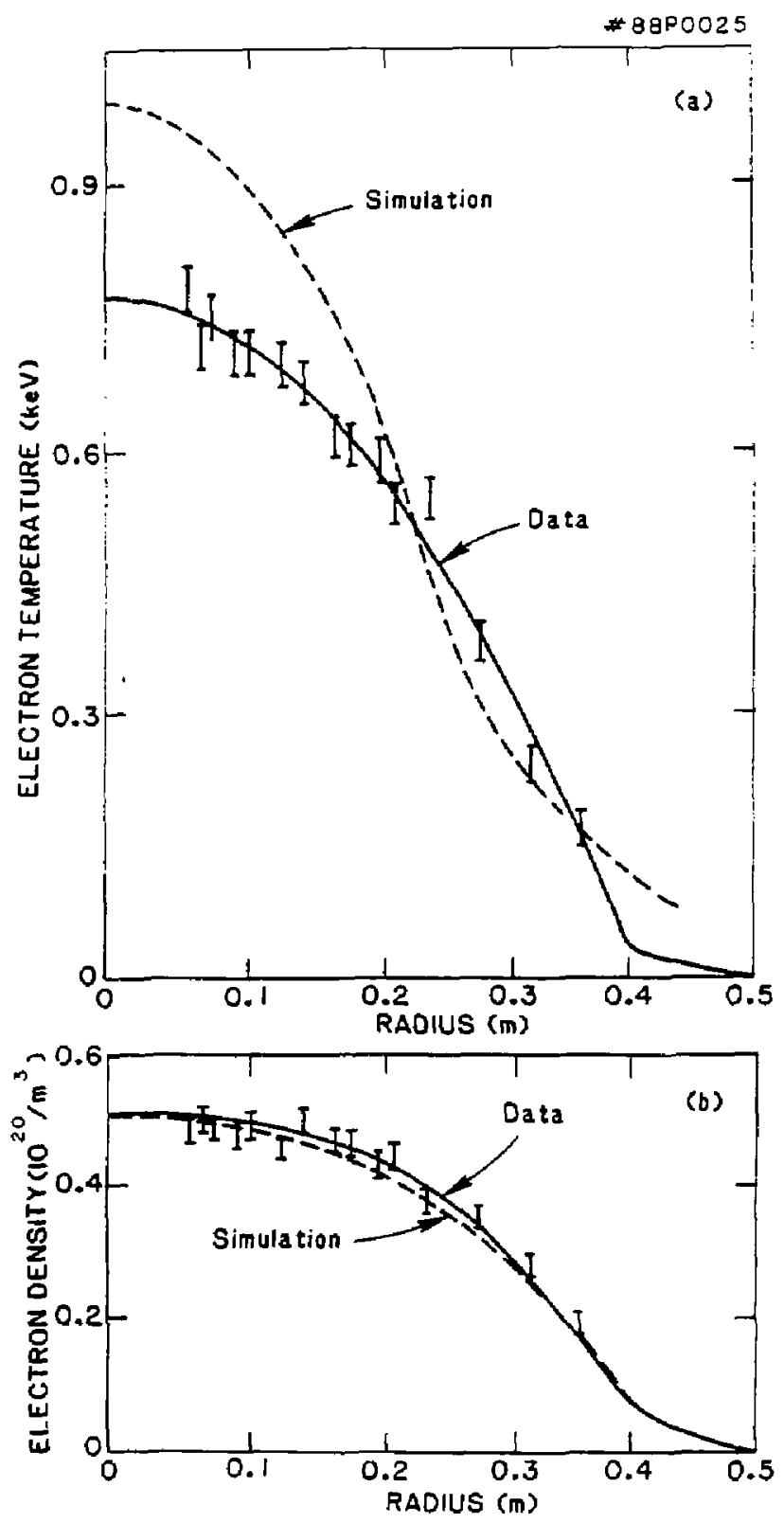

FIG。 4 

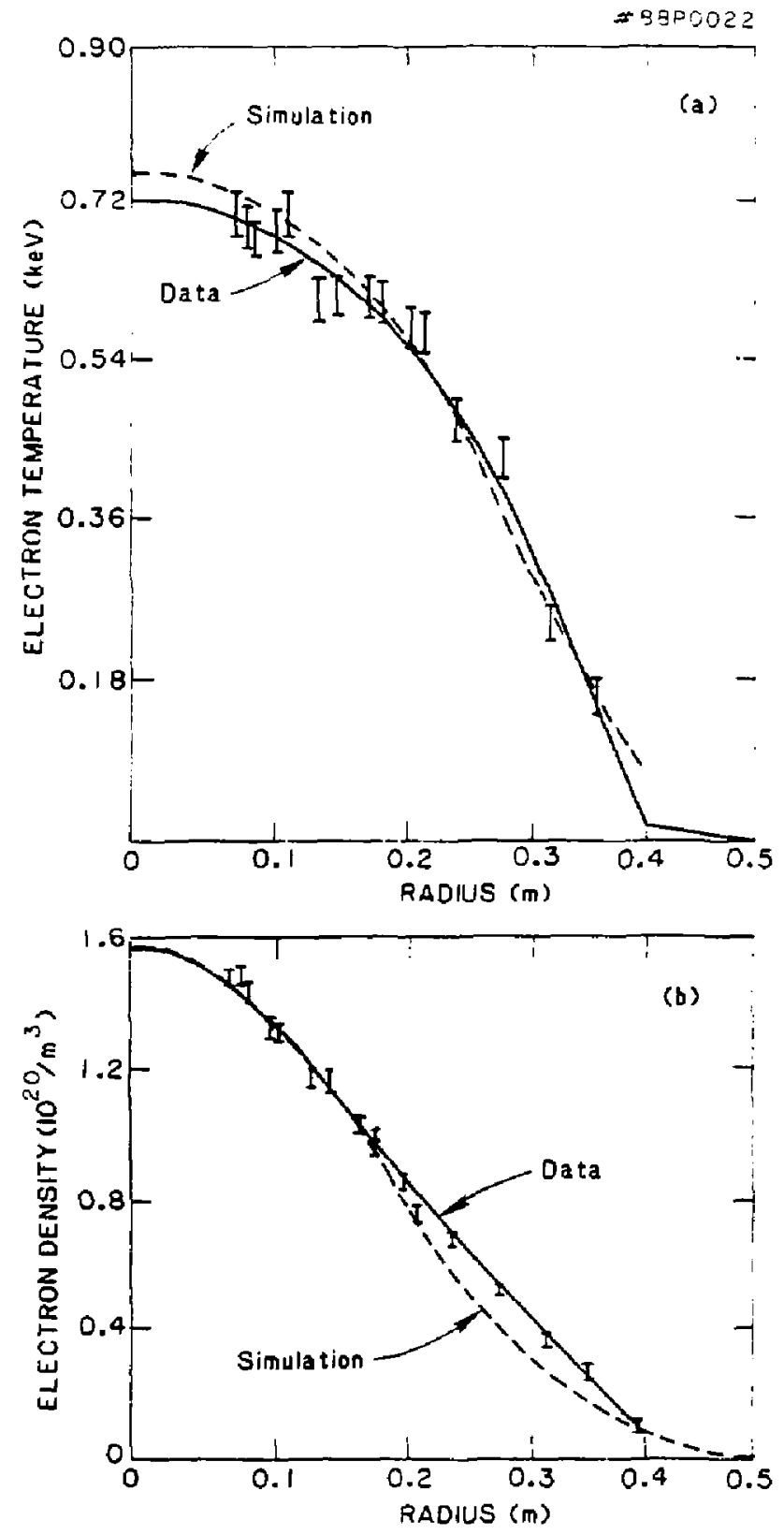

FIG. 5 

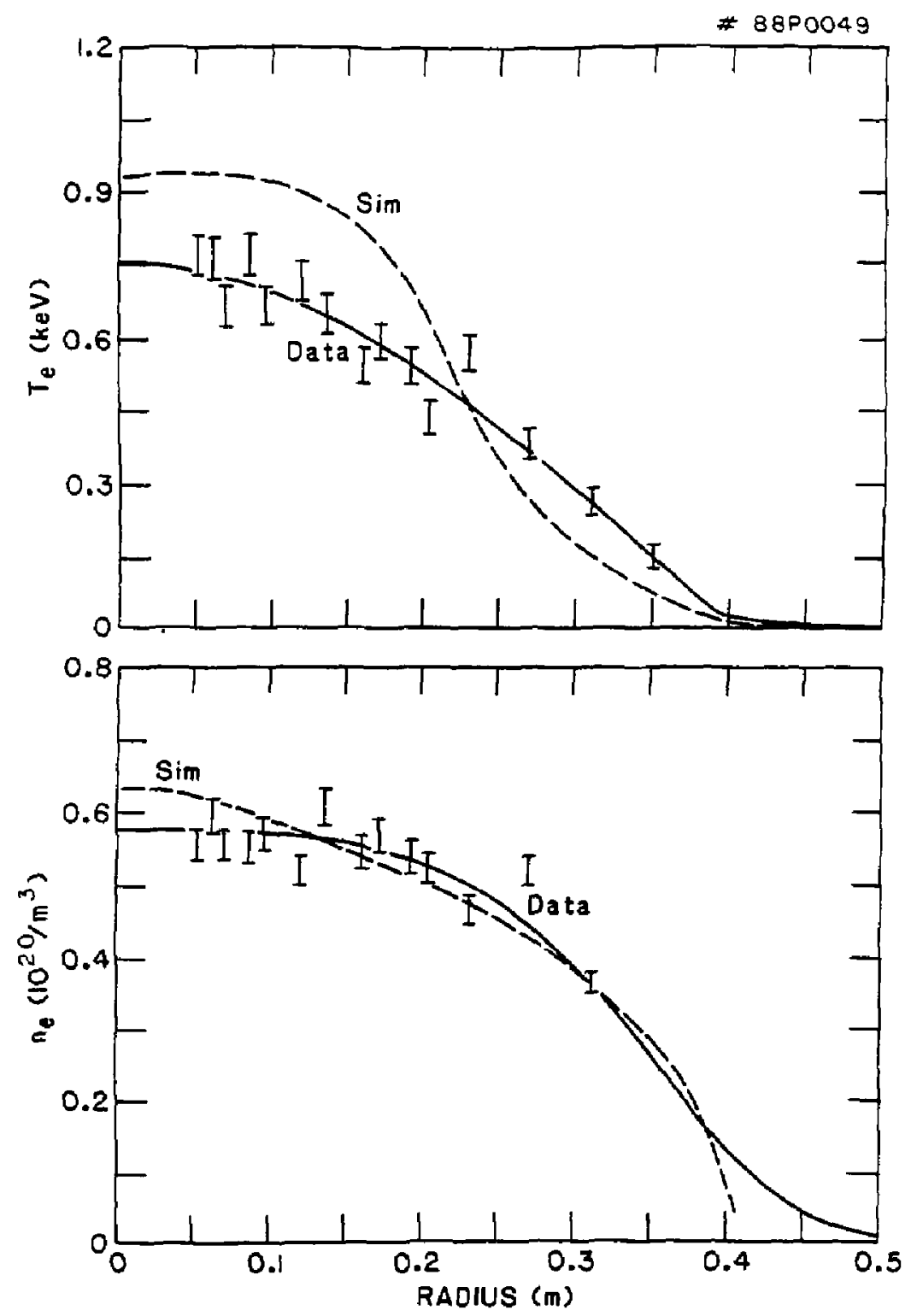

FIG. 6 

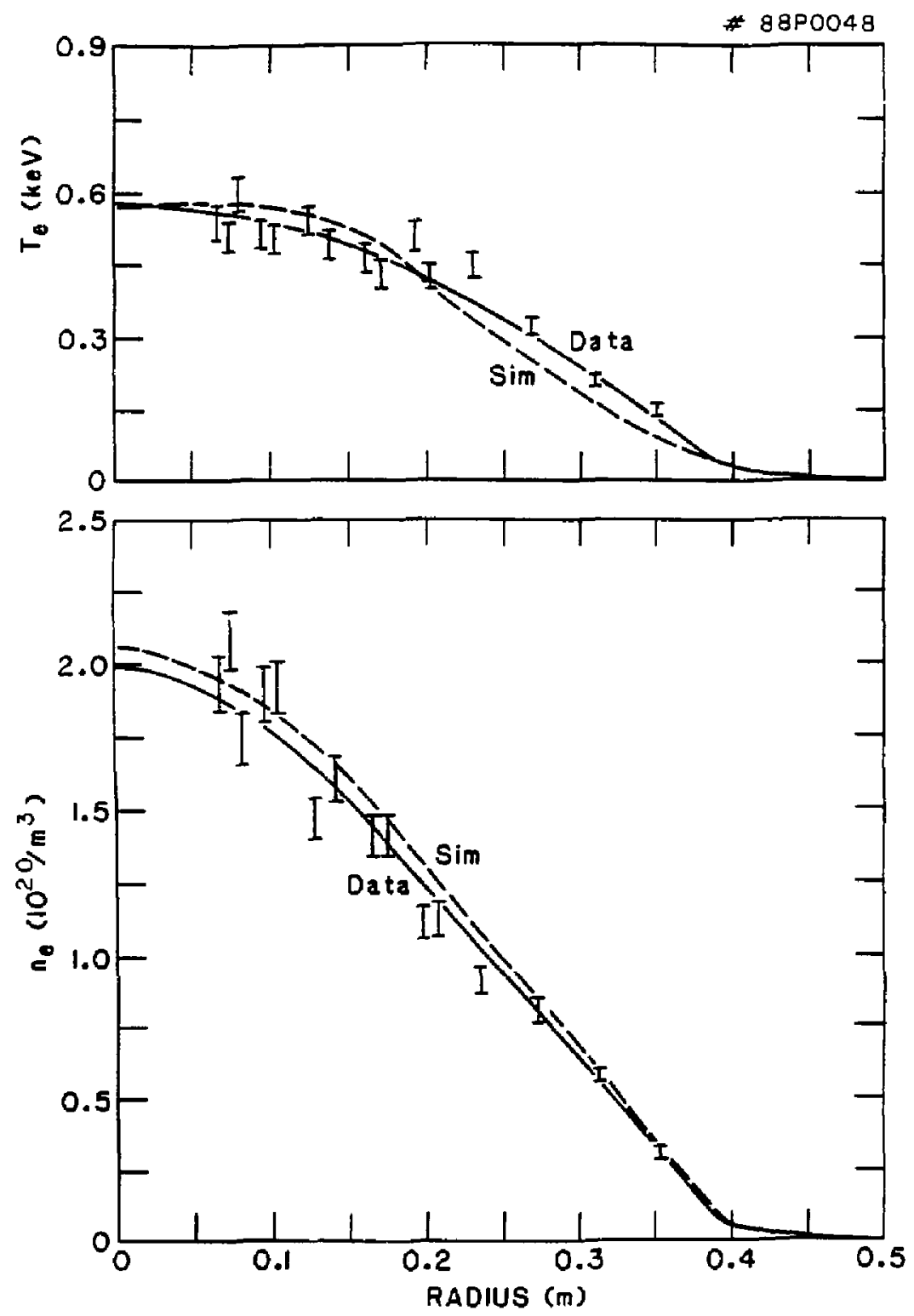

FIG. 7 

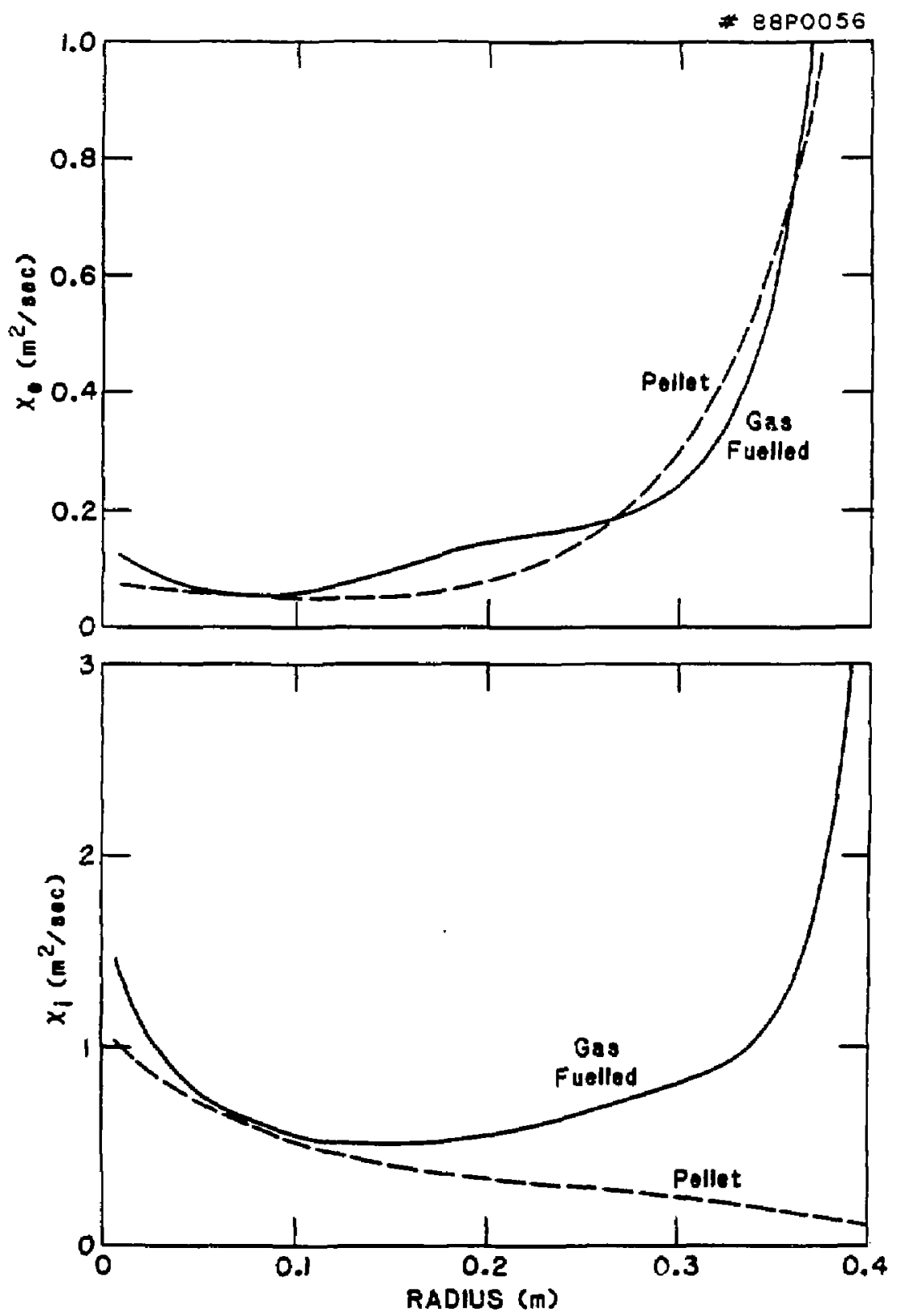

FIC. 8 

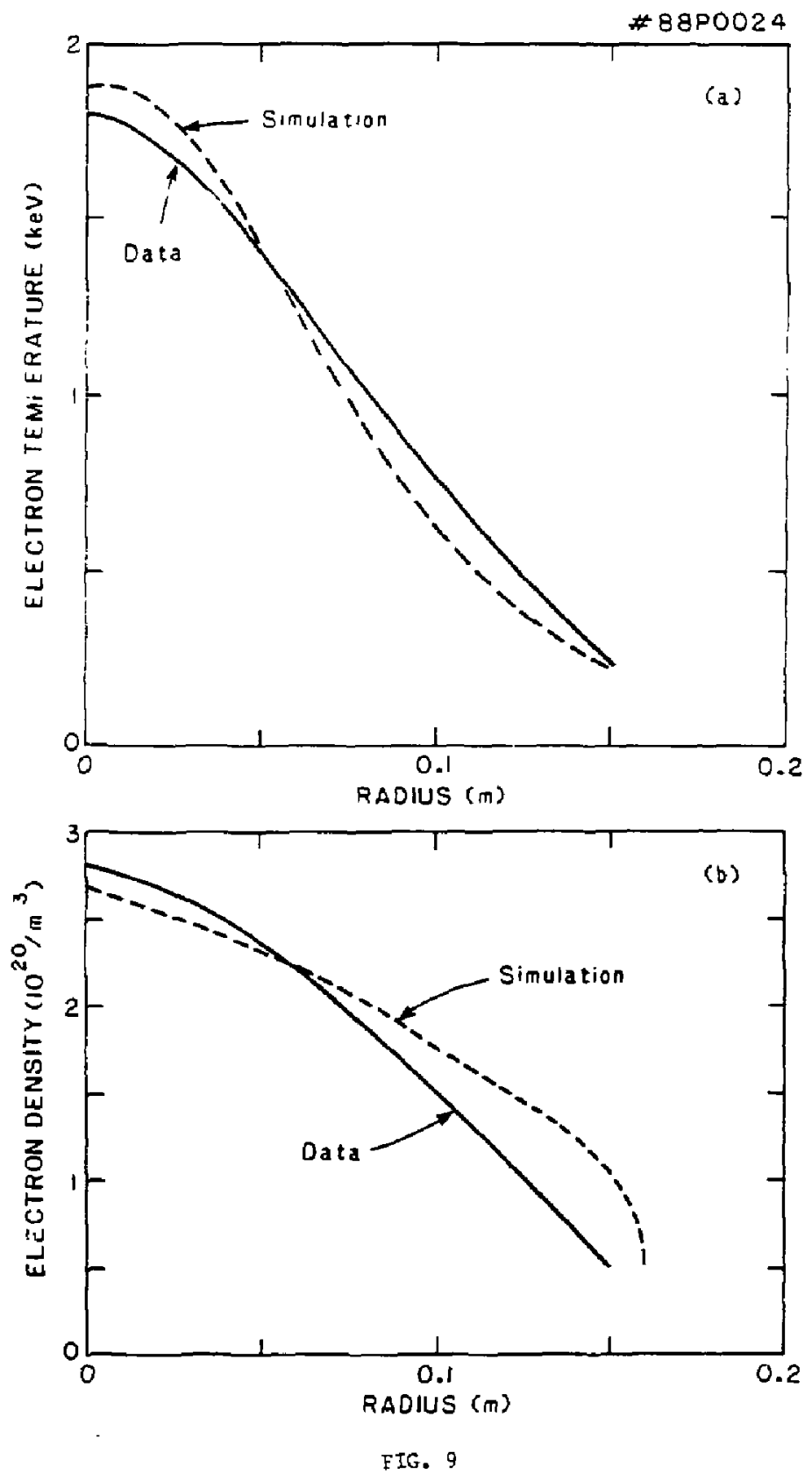

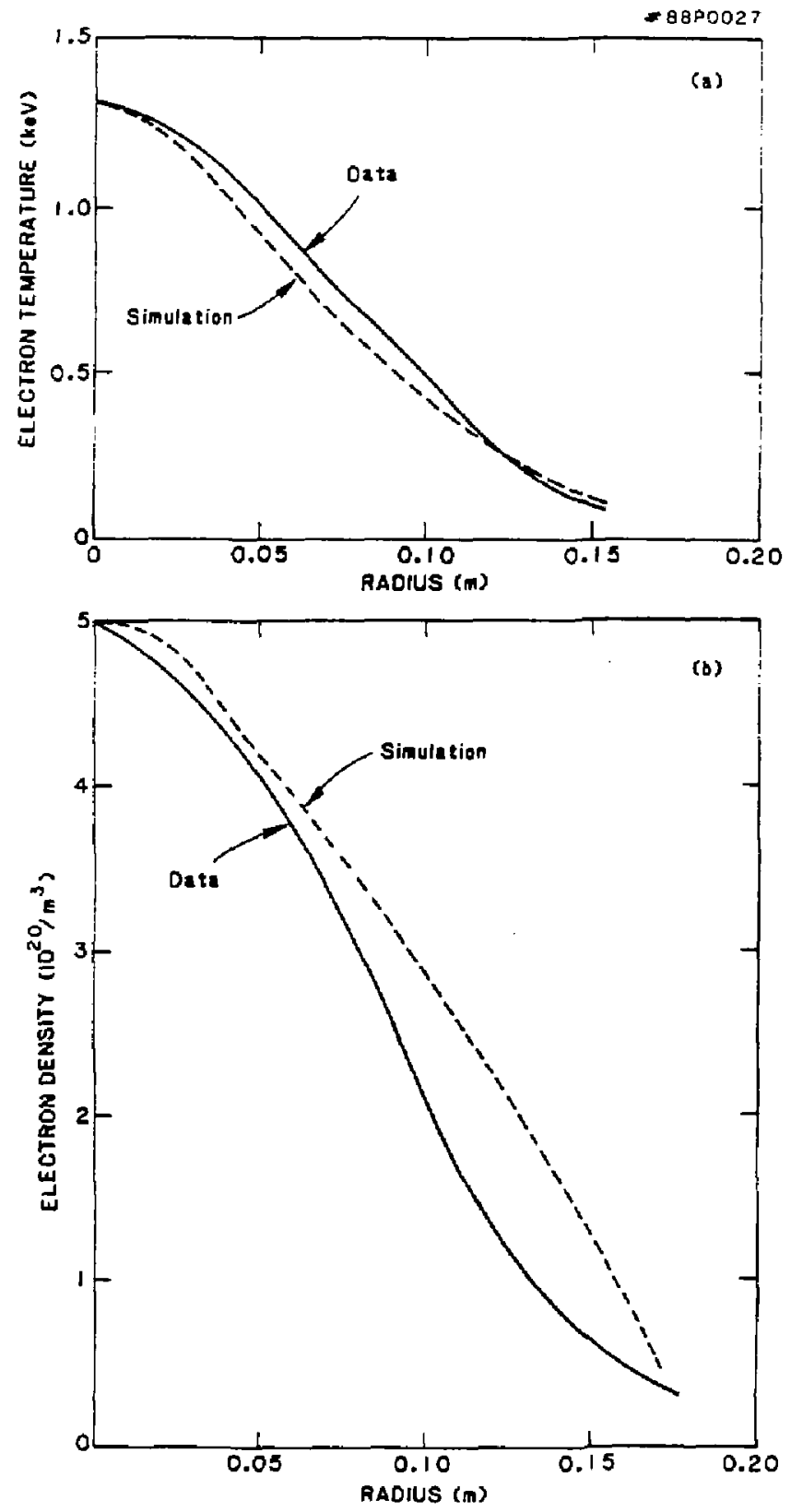

FIG. 10 

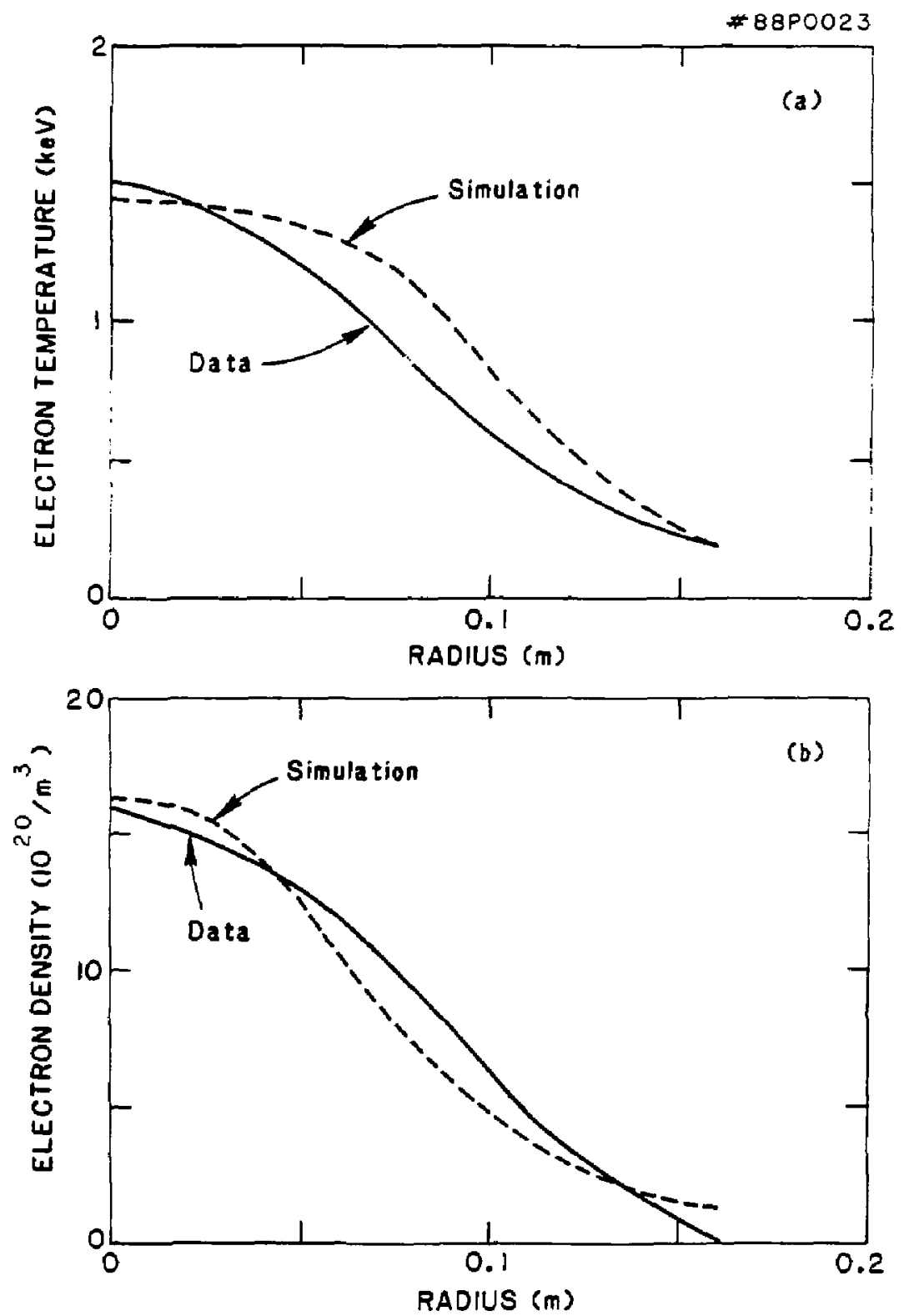

FIG. 11 
Or. Frank J. Paoloni, Univ of Wol longong, AUSTRALIA Prot. M.H. Grennan, Univ Sydrey, AUSTRALIA

Plasma Researen lab., hustratian Nat. Univ., AUSTRLlia Prof, I.R. Jones, Flindars Univ., AUSTRaLIA

Prol. F. Cao, Inst Theo Phys, AUSTRIA

Prof. H. Heindler, institut fur Theoretische Physlk, AUSTRIA

M. Coossens, Astronomisch instituut, BELGIUM

Ecole Rovale Mititaire, Lab de Phys Plasmas, BELgivu

Comission-Eurogean, Og-X/I Fusion Prog, BELGIuM

Prof, R. Boucique, Laboratorín voor Hatuurkunde, BELGIUA

Dr. P.H. Sakanaka, Instituto Fisica, BRAzIL

Instituto De Pesquises Espaciosi-INPE, BRAzIL

Documents Office. Atomic Enargy of Canada Limitad, Cakada

Or. M.P. Bachynski, WPB Technologies, I nc., CArkOA

Dr. H.M. Skarsgard, University of Saskatchawan, CANADA

Dr. H. Barnard, University of British Columbla, CANADA

Prof. J. Teichmann, Univ. of Montraal, CAMAOA

Prof. S.R. Sreenivasan, University of Calgary, CAMAOA

Prot. Tudor W. Johnston, INRS-Enurgie, CaNaDA

Dr. C.R. Jases, Univ, of Alberto, CAmDa

Dr. Peter Lukac, Komangkeho Univ, CZEOJOSlovakiA

The Librarian. Culham Laboratory, ENGLAD

The Librarian. Rutherford ADD!eton Laboratory, ENGLAND

wrs. S.A. Hutchinson, JET Library. EMGLANO

C. Mouttot, LAD. de Physique des Milioux Ionisos, fRAMCE

1. Radat, CEN/CADARACTE - Bat 506, FRANCE

Univ, of loonnina, Librory of Physies Dopt. GREECE

Dr. Ton Mual, Acadeay Bibliographic Sar., Hong Kong

Praprint Library. Hungari on Acadear of Sciences, Mungapy

Dr. B. Dasqupta, Saha Inst of Nuc!. Phys., INDIA

Dr. P. Kaw, Institute for Plasad Research, INDIA

Dr. Philito Rosenau, Israel Inst. Tech, ISRAEL

Librarian, Int'I Ctr Theo Phys, ITALY

Prat. G. Rostagni, Univ Di Padova, ITALY

Miss Clelia Do Palo, Assoc Eupatan-ENeA, ITALY

Biblioteca, instituto di fisica del Plasme, ITALY

Dr. H. Yacato, Toshide Ras a Der, JAPAN

Prof. 1. Karakani, Atomic Energy Ras. Institute, JAPAN

Prof. Kyoji Hishikowo, Univ of Hiroshime, JNPAY

Direc. Dept. Large Tokenak Rot. JAERI, JAPAN

Prot, Satoshi Itoh, Krushy University, JAPAN

Rusearen info Center, Nagoys University, JAPAN

Prof. 5. Tanako, Kyoto Univarsity, JAPAN

Library. Kyoto university, INPAN

Prof. Nobuyuki Inout, University of Tokyo, JAPAN

S. Mor $i$, JAERI, JAPAN

Librarian, Kores Advanced Energy Res. Institute, KOREA

Prof. D.1. Choi, Adv, Inst 5el \& Tach, KOPEA

Prof. B.S. Liley, University of Waikato, NEW ZEALAND

institute of Plasme Physles. PEOPLE'S REPUelic of CHIMA

Librarian, Institute of Phys.., PEOPLE'S REPUBLIC OF CHINA

Library, Tsing Hua Univarsity, PEOPLE'S REPUBLIC OF CHINA
2. Li, Southmest Inst. Physics, PEOPLE'S RePublic OF CHINA Prot. J.A.C. Cabral, Inst Suderior Tecnico, PORTUGAL Dr. Oetavian Patrus, AL I CUZA University, ROMANiA Dr. Johan de Villiers, Fusion Studies, AEC, SO AFRICA Prot. M.A. Helliberg, University of Natal, SO AFRICA C.I.E.M.A.T., Fusion Div. Library, SPAIN Or. Lennart Stentla, University of UMEA, SWEDEN Librery, Roysl inst Toch, SWEDEN

Crui. Hans WIIhelmson, Chalmers Univ Tech, SHEDEN

Cantro Phys des Plasmas, Ecole Polytech Fed, SWITzERLARo

Gibliotheak, Fon-lnst yoor Plasma-Fysica, THE NETHERLAnOS

Dr. D.D. Ryutov, Siberian Acad Sci, USSR

Dr. G.A. El iseav, Kurchatoy lagtitute, USSR

Dr. V,A. GIukhikh, Inst Electrophysical AdDaratus, USSR

Dr. V.T. Tolok, Inst. Phys, Toch, USSR

Dr. L.M. Kovrlizhnykn, Institute Cen, Physics, USSR

Nuclear Res. Establ isheant, Jul ich Lto., W. GEFaMnY

Bibliothak, Inst. Fur Plasmaforsenung, W. GEPMANr Dr. K. Schindlar, Ruhr Univers itat Bochum, W. GEFMANY ASDEX Raading Ro, IPPMAaxtlanck-Institut fur

Plasodphysik, W. GERANY

Librarian, Max PIanck Institut, W. GEPGANY

Prof. R.K. Janer, Inst Phys, rucosLavia 